\title{
WestVirginiaUniversity
}

THE RESEARCH REPOSITORY @ WVU

Graduate Theses, Dissertations, and Problem Reports

2017

\section{Studies on Entrepreneurship, Regulation and Economic Freedom}

Sriparna Ghosh

Follow this and additional works at: https://researchrepository.wvu.edu/etd

\section{Recommended Citation}

Ghosh, Sriparna, "Studies on Entrepreneurship, Regulation and Economic Freedom" (2017). Graduate Theses, Dissertations, and Problem Reports. 5670.

https://researchrepository.wvu.edu/etd/5670

This Dissertation is protected by copyright and/or related rights. It has been brought to you by the The Research Repository @ WVU with permission from the rights-holder(s). You are free to use this Dissertation in any way that is permitted by the copyright and related rights legislation that applies to your use. For other uses you must obtain permission from the rights-holder(s) directly, unless additional rights are indicated by a Creative Commons license in the record and/ or on the work itself. This Dissertation has been accepted for inclusion in WVU Graduate Theses, Dissertations, and Problem Reports collection by an authorized administrator of The Research Repository @ WVU.

For more information, please contact researchrepository@mail.wvu.edu. 


\title{
Studies on Entrepreneurship, Regulation and Economic Freedom
}

\author{
Sriparna Ghosh \\ Dissertation submitted \\ to the College of Business and Economics \\ at West Virginia University \\ in partial fulfillment of the requirements \\ for the degree of
}

Doctor of Philosophy in

Economics

Joshua C. Hall, Ph.D., Chair
Bryan C. McCannon, Ph.D.
John Deskins, Ph.D.
Peter Calcagno, Ph.D.
Department of Economics

Morgantown, West Virginia

2017

Keywords: Firm exit, Entrepreneurship, Regulation, Economic Freedom Copyright 2017 Sriparna Ghosh 


\begin{abstract}
Studies on Entrepreneurship, Regulation and Economic Freedom
\end{abstract}

Sriparna Ghosh

This dissertation is a collection of empirical essays studying the effects of institutional qualities on firm dynamics and latent entrepreneurship. After providing an overview of the dissertation in Chapter 1, in Chapter 2 I analyze the effect of industry level federal regulations on firm decisions to exit the market. The idea is to test whether stricter regulation results in reduced competitiveness for smaller firms relative to larger firms. Using data from the Kauffman Firm Survey and RegData, I find that the effect of regulation on firm exit varies based on firm size. My findings are in congruence with the predictions of regulator models where regulation acts as a fixed cost on all firms, leading to a reduction in small firms relative to large firms.

In Chapter 3, I look at the effect of economic freedom on entrepreneurial intention. While a number of studies have looked at the effect of economic freedom on entrepreneurship, none have looked at how economic freedom influences the intention to engage in entrepreneurship. Using panel data on a wide variety of countries, I investigate the effects of economic freedom, especially regulation, on entrepreneurial intention. My findings suggest that stricter credit market regulation reduces entrepreneurial intention whereas more stringent labor regulations restricts job availability and thereby encourages more people to take up entrepreneurship as a career choice.

Chapter 4 is an addition to the literature on economic freedom and economic growth. It has been well-established that economic freedom is associated with good economic outcomes. Economic freedom, however, is comprised of numerous dimensions. The marginal benefit to improving policy in one area can be expected to depend on the amount of freedom in the other dimensions. Thus, which policy improvement is most impactful depends on the entire menu of current policies and, therefore, differ between states. In Chapter 4, Bryan McCannon and I explore how economic freedom measurements can be used to guide policy. We propose a method for creating a growth-enhancing economic freedom index, which allows for nonlinearities and interaction effects between the components to economic freedom. We use this method to illustrate that U.S. states differ in which policy area generates the greatest gains. To validate our method, we apply our index to state bond markets. If our measurement is useful, then it should correlate with bond ratings. Consistent with this hypothesis, we find that state bond ratings are strongly correlated with our growth-enhancing economic freedom index. 


\section{Dedication}

This dissertation is dedicated to my parents, Dr. Apurba Kumar Ghosh and Ashoka Ghosh and my grandmother Shefali Ghosh, who are my pillars of support. 


\section{Acknowledgements}

I am extremely grateful to my advisor Dr. Joshua Hall for being so encouraging and supportive. His dedication towards research, passion for teaching and commitment towards work inspired me to be an academician. I owe him all my current and future achievements.

I am also indebted to Dr. Stratford Douglas who has constantly encouraged and supported me. I am also thankful to remaining members of my committee Dr. Bryan McCannon and Dr. John Deskins for their comments, guidance, and suggestions which helped make this dissertation possible. I also want to thank Dr. Umair Khalil and Dr. Arabinda Basistha for their valuable contributions.

I would like to thank Dr. Randall Jackson and every one at Regional Research Institute for being a family to me. I am specially thankful to Karen Smith for providing wonderful administrative support for last five years. I would also like to honor the immense contribution of my teachers Dr. Zakir Husain, Dr. Mousumi Dutta, Dr. Rupa Chanda, Dr. Debabrata Datta and Sukanta Datta. I am deeply grateful to my classmates and friends Shreebaba Pokharel, Danko Tarabar, Imran Arif and John Meszaros who have been with me throughout my graduate life at WVU. I would not have reached this far without the unconditional love and support of my parents, Dr. Apurba Kumar Ghosh and Ashoka Ghosh. I am also incredibly thankful to my friends Dr. Punarjit Roychowdhury, Dr. Arkamitra Kar, Dr. Indranil Biswas, Hasan Latif and my brother Satyajit Das for providing me relentless support throughout my tenure as a doctoral scholar. 


\section{Table of Contents}

List of Figures vii

List of Tables viii

1 Introduction $\quad 1$

2 Firm Exit: Does Regulation Matter? 3

2.1 Introduction . . . . . . . . . . . . . . . . . . . 3

2.2 Background . . . . . . . . . . . . . . . . . . 6

2.3 Data . . . . . . . . . . . . . . . . . . . 9

2.3.1 The Kauffman Firm Survey . . . . . . . . . . . . . . . . . 9

2.3.2 The Regulation Data . . . . . . . . . . . . . . . . . . . . 11

2.3.3 Controls . . . . . . . . . . . . . . . . . . . . 14

2.4 Empirical Model . . . . . . . . . . . . . . . . . . . . . 15

2.4.1 Parametric model . . . . . . . . . . . . . . . . . . 18

2.4.2 Semi parametric model . . . . . . . . . . . . . . . . . 19

2.5 Results . . . . . . . . . . . . . . . . . . . . . . . . . . . . . . . . . . . . 20

2.6 Conclusion . . . . . . . . . . . . . . . . . 22

3 Regulation and Entrepreneurial Intention $\quad 30$

3.1 Conceptual Framework . . . . . . . . . . . . . . . . . . 33

3.2 Empirical specification . . . . . . . . . . . . . . . . . 35

3.3 Data . . . . . . . . . . . . . . . . . 36

3.3.1 Dependent Variable . . . . . . . . . . . . . . . . . . . . . . . . . . . . . . . 36

3.3.2 Independent Variable . . . . . . . . . . . . . . . . . . . . . 37

3.4 Results . . . . . . . . . . . . . . . . . . . . . . . . . 39

3.5 Conclusion . . . . . . . . . . . . . . . . . . . . 42

4 Growth-Enhancing Economic Freedom $\quad 50$

4.1 Introduction . . . . . . . . . . . . . . . . . 50

4.2 Economic Freedom and Research Findings . . . . . . . . . . . . . 52

4.3 Data . . . . . . . . . . . . . . . . . . . 55

4.4 Results . . . . . . . . . . . . . . . . . . 56

4.5 Using the GE-EFNA . . . . . . . . . . . . . . 60 
TABLE OF CONTENTS

4.6 Conclusion . . . . . . . . . . . . . . . . . 64

$\begin{array}{lll}5 & \text { Conclusion } & 75\end{array}$ 


\section{List of Figures}

2.1 Exit Rates of firms by Regulation . . . . . . . . . . . . . . . 29

4.1 Economic Freedom over Time . . . . . . . . . . . . . . . . . . . . 74 


\section{List of Tables}

2.1 Summary Statistics . . . . . . . . . . . . . . . . . . 23

2.2 Status of the firm by year . . . . . . . . . . . . . . . . . 24

2.3 Survival Analysis . . . . . . . . . . . . . . . . . . . 25

2.4 Survival Analysis for merger and acquisition . . . . . . . . . . . 26

2.5 Survival Analysis with state regulation . . . . . . . . . . . . . 27

2.6 Description of variables . . . . . . . . . . . . . . . . . 28

3.1 Summary Statistics . . . . . . . . . . . . . . . . . . . . . 44

3.2 Effect of Regulation on Entrepreneurial Intention . . . . . . . . . . 45

3.3 Effect of Regulation on Entrepreneurial Intention with controls . . . 46

3.4 Effect of Regulation on Entrepreneurial Intention with Country and year Fixed effects . . . . . . . . . . . . . . . . . . . 47

3.5 Effect of Regulation on Entrepreneurial Intention with interpolated data 48

3.6 Effect of Regulation on Entrepreneurial Intention excluding countries with less observations . . . . . . . . . . . . . . . . . . . . . . . . 49

4.1 Descriptive Statistics . . . . . . . . . . . . . . . . . . 66

4.2 Growth-Enhancing Economic Freedom . . . . . . . . . . . . . . . 67

4.3 Marginal Impacts of Improved Economic Freedom . . . . . . . . . . . 68

4.4 Descriptive Statistics . . . . . . . . . . . . . . . . . . . 69

4.5 Economic Freedom and State Bond Rating . . . . . . . . . . . . . . . 70

4.6 Growth-Enhancing Economic Freedom . . . . . . . . . . . . . . . 71

4.7 Goodness of Fit of Alternative Specifications . . . . . . . . . . . . . . 72

4.8 Growth-Enhancing Economic Freedom . . . . . . . . . . . . . 73 


\section{Chapter 1}

\section{Introduction}

Small businesses act as a major channel for job creation and economic growth. According to the Small Business Administration (SBA), small businesses constitute 99.7 percent of U.S firms and were responsible for 64 percent of the net new jobs created between 1993 to 2011. High federal regulation can be detrimental to small businesses as they struggle to comply with high fixed costs regulation. According to a report published by Small Business Trends the estimated compliance cost with federal regulation per employee is around 10,585 for small businesses having less than 20 employees. Moreover, complying with regulatory burdens can lead to a decrease in competitiveness for small firms . The Swedish Agency for Growth Policy Analysis (2010) confirms that regulatory burden hampers new firm productivity and entrepreneurial growth. Higher federal regulation might affect the survival of firms, particularly smaller firms having fewer than 100 employees. The survival and growth of small firms are essential for the economy to grown and expand. Apple, Microsoft, Netscape are examples of relatively young firms that stared out small. These companies are evidences of exceptional entrepreneurship and have enormous effect on computer industry. According to Schumpeter (1934) and Stevenson (1983) entrepreneurship is defined as "taking advantage of opportunity by novel combination of resources in ways which have impact on the market."

In this thesis I examine the effect of regulations on firm survival and aspiring 
entrepreneurs in developed and developing countries. Chapter 2 focuses on the effect of federal regulations on the survival rate of small firms with fewer than 100 employees. While most of the literature (Klapper et al., 2006; Djankov et al., 2002) focuses on the effect of regulation on firm entry, regulation might be inimical to survival of firm as well. This paper contributes to the literature in terms of investigating the effect of industry-level federal regulations on firm survival. Using firm-level data from the Kauffman Firm Survey and industry-level regulation data from RegData, I use hazard models to verify how firm survival differs according to firm size.

Whereas Chapter 2 emphasizes on a micro outlook on firm dynamics, Chapter 3 focuses on the effect of the regulatory framework on nascent entrepreneurship across countries. While the literature mostly focuses on entrepreneurial activity, I have used entrepreneurial intention which is an overall latent entrepreneurs. I have used an unbalanced panel for 79 countries from 2001 to 2016 from the Global Entrepreneurship Monitor to find that people are more willing to take up entrepreneurship as a career choice in a developing country with better institutional qualities, measured by the Economic Freedom of the World annual report.

In Chapter 4, jointly with Bryan McCannon, we use the state-level level Economic Freedom of North America data to guide policy implications. The Economic Freedom of North America (EFNA) equally weighs three areas: size of government, labor and taxes. We propose a method for creating a growth-enhancing economic freedom index (GEEFNA) which rather than equally weighing the areas, constructs an econometric fit between EFNA and real GDP per capita. This index helps us to choose the respective area per state which yields maximum growth. The idea is if we have to choose a particular aspect of economic freedom based on maximizing economic growth, the index will help us to do so. We also test the index and find that GEEFNA provides a better forecast of state's bond ratings. 


\section{Chapter 2}

\section{Firm Exit: Does Regulation Matter?}

\subsection{Introduction}

A large body of literature has emerged over the last few years those empirically analyze the effect of entry regulations on firm entry (Djankov et al., 2002; Klapper et al., 2006; Bailey and Thomas, 2015). These studies have found evidence of high barriers to entry resulting in a reduction in the firm entry. Additionally, these studies also find that incumbent firms often support high regulation in order to secure their position against new firms which is in line with the predictions of early theoretical works of Tullock (1967), Stigler (1971), and Peltzman (1976).

While most of the literature connecting regulation to firm dynamics focuses on the effect of regulation on firm entry, it is often argued that higher or stricter regulations not only act as a barrier for the firm to enter the market, but can also induce some firms to leave the market and lower the level of competitiveness in the market. This may be because, as posited by the neoclassical theory of firm dynamics, stricter regulations act as an increase in fixed cost leading to decrease in the proportion of smaller firm in the market who fail to comply with the higher regulatory cost. On the contrary, given the fixed cost nature of complying with regulation, higher regulation 
may give a cost advantage to comparatively larger size firms, leading to less large firms leave the market (Thomas, 1990; Acemoglu and Angrist, 2001; Nooteboom, 1993; Calcagno and Sobel, 2014). Thus, given that the effect of regulation on firm exit is likely to vary by firm size (Ardagna and Lusardi, 2010), an increase in regulation is likely to result in a lower level of market competitiveness by accelerating the rate of exit of smaller firms from the market and providing a cost advantage to larger firms.

The above discussion clearly suggests that the analysis of the link between regulations and firm exit is crucial for understanding industry dynamics in general and for designing effective industrial policy. However, this has not received much attention in the existing literature. The goal of this paper is to fill this gap in the literature on regulation and firm dynamics by investigating the effect of regulation on firm exit. The main hypothesis that I seek to test is the following: stricter regulations result in lower competitiveness resulting from the majority of smaller firms leaving the market and only large firm still surviving in the market. I have done a survival analysis which investigates the effect of regulation on firm's exit decision.

The data come from the Kauffman Firm Surveys (KFS). KFS follows firms who were established in 2004 through 2011, providing individual level information on firms. As KFS followed each particular firm through eight years, this gives an opportunity to investigate the effect of stricter industry specific regulation on each firm's exit decision. Furthermore, detailed information regarding the financial condition, employee size and demographics of the owner not only allows me to control various firm characteristics but also provides me with the opportunity to analyze whether the effect of regulation on firm exit varies on the basis of firm size.

In order to take into consideration how firm size along with regulation affects firm exit, I perform survival analysis, incorporating firm size based on number of employees. Since the duration of the firm in the market varies with different firm leaving the market at different point of time starting from 2005 to 2011, I do a survival analysis in order to capture the effect of higher regulation on firm's exit decision. A large body of literature (Dunne et al., 1988; Audretsch and Mahmood, 
1994; Sutton, 1997; Agarwal and Audretsch, 2001; Mata and Portugal, 1994; Mitchell, 1994; Haveman, 1995; Sharma and Kesner, 1996; Geroski et al., 2010) argue that duration of firm survival is dependent on firm size. In this paper, I have linked two strands of literature to argue that regulation (both state and industry level federal regulation) has diversified effect on firm survival. To my knowledge, this is the first study to use hazard models to analyze the effect of industry level regulation on firm exit based on different time of the occurrence of the event, that is, firm exiting the market.

My results show that regulation acts as a fixed cost and leads to a reduction in small sized firms in the market whereas large firms are more likely to survive as regulation becomes stricter. Using survival analysis yields to same results which states that higher federal regulation has a negative impact on smaller size firms whereas stricter regulation has a positive effect on large firms. The effect of regulation on firm survival is contingent upon the firm size (I have used total number of employees as a proxy for firm size), higher regulation is detrimental to small sized firms (having employee size less than 100) whereas bigger (more than 100 employees) firms enjoy the comparative advantage as regulation increases.

Empirical literature on the effect of regulation on firm exit is scarce. Thomas (1990) evaluates the effect of regulation on the number of firm deaths and found that regulation does not have any significant effect on overall firm death. They find, however, evidence that a 10 percent increase in regulation is associated with up to 0.9 percent reduction in deaths of large firms. This result is in line with the argument that incumbents generally prefer to have higher regulation (Tullock, 1967; Stigler, 1971; Peltzman, 1976).

This paper contributes to the existing literature on the effect of regulation on firm behavior in at least two ways. First, it is among the first few papers that examine the impact of industry level regulation on firm exit. By complementing the existing empirical work that looks at how entry regulations affect firm entry, this paper thus deepens the general understanding of the impact of regulatory framework on firm's 
business decisions. Second, this paper adopts a micro-point of view in understanding how regulations affect firm survival based on firm size. In particular, it uses very detailed firm level data to investigate firm behavior. This is in contrast to many previous papers that use country level data. One problem of these studies is that, by using macro level data, these studies fail to take into account that regulations which a startup firm faces have significant variation within countries. In addition, country wise regulation measures also fail to take into account the industry specific regulatory measures. ${ }^{1}$ Among the existing papers, that adopt a micro level approach to analyze firm dynamics, Bailey and Thomas (2015) were the first to use industry specific regulation data. They examine the impact of higher regulation on firm entry in context of the United States. ${ }^{2}$ However, unlike them, my focus is to analyze the link between industry-level regulations and firm survival.

The rest of the paper is organized as follows. Section 2 presents the theoretical framework. In Section 3, I discuss the data. The empirical strategy is presented in the next section. Section 5 presents the results. The last section concludes.

\section{$2.2 \quad$ Background}

A large body of literature (Dunne et al., 1988; Audretsch and Mahmood, 1994; Sutton, 1997; Agarwal and Audretsch, 2001; Mata and Portugal, 1994; Mitchell, 1994; Haveman, 1995; Sharma and Kesner, 1996; Geroski et al., 2010) provide positive evidence in favor of the fact that likelihood and the duration of firm survival is dependent on firm size. According to Audretsch and Mahmood (1994), larger firms are less prone to leave the market because they operate close to the minimum efficient scale of operation compared to the small firms. Following the argument of Bradford (2004), large firms might have economies of scale of operation simply because resources are cheaper when bought in bulk. Bradford (2004) further argues that economies of scale

\footnotetext{
${ }^{1}$ Klapper et al. (2006) use a 'natural propensity score', which indicates whether a given industry exhibits a naturally high trend for firm entry, in order to correct for country wise regulation measure.

${ }^{2}$ Bailey and Thomas (2015) use the RegData database of the Mercatus Center at George Mason University.
} 
might arise from the fact that a firm with higher employee size might hire a full-time coordinator whose main job is to report violation of anti-discrimination laws while a small sized firm might not be able to afford a full-time employee for this purpose. Various other factors like indivisibility of resources and regulation associated to hiring contribute towards higher regulatory cost affecting the survival rate of the firm. ${ }^{3}$

Moreover, the size of the firms are related to other factors like access to funds, diversification of investments or better managerial capabilities (Lucas Jr, 1978). These factors are not only related to the size of firms but are also responsible for the survival of firms. Furthermore, large firms have more flexibility to cut expenditure during a downturn compared to the small firms who are limited by their small scale of operation. This is one of the major reason for higher failure rates of small firms compared to the large firms. These above factors make it clear that survival of a firm is closely related to the firm size. Following Mata and Portugal (1994), Geroski et al. (2010), and Calcagno and Sobel (2014), I use the number of employees in the firm as the measure of firm size for my survival analysis.

As mentioned before, the literature has focused on effects of various firm level characteristics on firm survival. However, there is still a dearth of empirical literature analyzing firm survival rates. One of the basic reason for survival analysis to be rare in literature is due to the lack of availability of appropriate longitudinal data which follows the individual firms for a long period of time. The KFS fills in the lack of availability of data not only in terms of following individual firms for a fairly long period of time but also surveying a large sample of firms. Previous studies have found positive relation between firm size and survival. Empirical research on survival analysis require data on large sample of firms. In order to perform survival analysis, the firms should be tracked from birth to exit or for a considerable period of time and should have short interval between follow up surveys. KFS is a unique dataset

\footnotetext{
${ }^{3}$ The problem associated with indivisibility of resources might lead to higher fixed costs (Stein, 1974). For example, if the Occupational Safety and Health Administration (OSHA) Law requires a portable toilet for every 30 workers, smaller firms also have to comply by the same regulation, but the firm having higher employment size can utilize the indivisibility of resources more exhaustively compared to smaller firms (Bradford, 2004).
} 
which meets all of the above criteria. Most of the literature uses data set which has one or more shortcomings. As for example, Åstebro and Bernhardt (2003) uses the "Characteristics of Business Owners" which repeats the survey after five years of gap between each round. KFS is a very unique dataset which followed 5000 firms starting from 2004 to 2011 or until the firm exited the market. In addition to the consistency of the survey period, KFS captures a wide variety of characteristics about the firm including firm characteristics, various details about the owners and also reports firms belonging to wide range of industries.

Given the richness of the KFS data, various aspects of the data has been used for analysis. Coleman et al. (2013) using KFS data investigates the gender differences in terms of using start-up capital and subsequent investment and concludes that women are more likely to rely on personal rather than external financing both for start-up capital and subsequent investments. Coleman et al. (2013) uses KFS data to analyze the effect of different types of resources like education and work experience of the owner and start-up capital on firm survival. Gai and Minniti (2015), using KFS intends to answer whether commercial financing can explain the gap between the performance and survival rates of white and black owned businesses. This paper contributes to the literature in terms of highlighting the fact that the effect of industry level regulation on firm survival varies by firm size.

Furthermore, until now most of the studies have investigated the effect of country and state level regulations on firm behavior (Nyström, 2008; Klapper et al., 2006; Sobel et al., 2007; Djankov et al., 2002). All these existing studies have used country or state level regulation whereas regulation varies across industries. Klapper et al. (2006), however uses an interaction term between an industry's natural propensity for new firm entry and country level regulation in order to measure the effect of market entry regulations on the entry of new firms and the growth of the incumbent firms. The level of regulation varies across industries and there is certainly a differential effect of regulation on firm behavior across industries. RegData by Al-Ubaydli and McLaughlin (2017) is a novel dataset which reports industry level federal regulation 
for the time period 1997-2012. According to Davies (2014) from 1997 to 2010, the least regulated industries showed maximum growth about 63 percent in output per person compared to heavily regulated industries showing only 33 percent growth. It is expected that the survival rates for firms will vary across industries.

\section{$2.3 \quad$ Data}

\subsubsection{The Kauffman Firm Survey}

The Kauffman Survey data is a panel study of new businesses starting in $2004{ }^{4}$ KFS annually tracks these businesses from their date of commencement to exit. KFS is one of the very few datasets which is a single cohort panel, that is, KFS monitors the same group of businesses over time, starting from 2004 to 2011 (or exit). This gives researchers the opportunity to study various topics regarding business evolution and characteristics of businesses including business financing, characteristics of owners, products, services, and business innovations. Monitoring businesses over time gives a unique chance to analyze the cause of failure of businesses, which is rare given the cross-sectional nature of most of the surveys.

The prerequisite of performing a sample survey is selecting a target population. The target population for KFS includes new businesses that started operating in the calendar year 2004 in the United States. KFS uses some inclusion and exclusion criteria to ensure that the businesses qualify to be a part of the target population. The inclusion and exclusion criteria for KFS are: i) to include businesses that started to operate as an independent business in 2004, or started operating by purchasing an existing business or by purchasing a franchise in 2004; ii) to exclude businesses that either belonged to a non-profit organization or were created as a branch of a pre-existing business; iii) include those businesses having legal status in 2004, for example, sole proprietorship, limited liability company, subchapter S corporation, C-

\footnotetext{
${ }^{4}$ KFS was authorized by Ewing Marion Kauffman Foundation to conduct the survey every year starting from 2004 and the survey was conducted by Mathematica Policy Research, Inc.
} 
corporation, general partnership, or limited partnership; iv) to include business that have fulfilled one or more of the following criteria a) business has received its employer identification number in 2004, b) business has used Schedule C or Schedule C-EZ to report business income on a personal tax return in 2004, for the first time in order to function as a sole proprietorship, c) the business payed state unemployment insurance for the first time in 2004 and d) the business made federal insurance contribution act payments for the first time in 2004 .

KFS data is constructed based on stratified sampling according to various industrial technological levels (High-tech, Medium-tech and non-tech). ${ }^{5}$ Stratification is a process of dividing the sample into homogeneous groups prior to sampling based on several characteristics. In this case, KFS used SIC codes to divide the population into different strata of businesses. Stratification ensures that same proportion of respondents belong to each strata leading to more homogeneous samples. In the first survey in 2004 a sample of total 4928 firms has been selected for the survey out of a stratified sample of 32,469 firms in the Dun and Bradstreet (D\&B) database that began in $2004 .{ }^{6}$ Mathematica Policy Research, Inc. located 90 percent of the businesses out of the total stratified sample. However, only 49 percent of these businesses that were located, completed the baseline survey. But the final sample consists of 4928 businesses that meet the eligibility criteria.

Furthermore, a relevant weighting scheme has been used to remove any selection bias or response bias resulting from attrition of firms from the survey sample and also ensures that the observations in the survey sample correctly represents the target population. For example, the final sample in KFS that represents the target population of new businesses is 4,928 . The estimated target population of new businesses started in 2004 , which meets the eligibility criteria, rounds up to 73,278 . The raw data might not be an appropriate representation of the target population without taking into consideration weighting. Before considering weights, $58.7 \%$ of businesses represented

\footnotetext{
${ }^{5}$ The technology criteria are selected on the basis of the definitions given by the business's Standard Industry Classification (SIC) code.

${ }^{6}$ There were 251,282 businesses in the D\&B database that year.
} 
non-tech firms whereas after weighting the sample of non-tech business represented $85 \%$ of the sample (which is the case for the target population).

KFS asks the firms several questions about the business activity indicators to mark the time of entry of the firm. The questions include whether the firm has paid the state unemployment tax and Federal Insurance Contributors Act taxes. Also, the firms should have legal status, an Employer Identification Number or be using a Schedule C to report business income on a personal tax return. To be eligible for the KFS firm survey, all the above activities should be done in 2004 and not earlier. The KFS also collects information on owner characteristics like education, gender, race, work experience and hours worked. Further firm-specific characteristics like legal status of the firm, industry to which firm belongs, the number of owners, the number of copyrights or patents are also available from the KFS data. KFS also collects data on several indicators representing the financial stability of the firm like assets, equity, debt financing, credit risk, profit, expenses, revenues etc.

\subsubsection{The Regulation Data}

I have used Reg Data by Mercatus Center to measure federal regulation. Reg Data is a measure of industry-specific federal regulations for all United States industries from 1997-2012. Several studies have used the number of pages of Federal Register as a measure of regulation (De Rugy and Davies, 2009; Coffey et al., 2016), whereas Dawson and Seater (2013) uses the number of pages in Code of Federal Regulations $(\mathrm{CFR})$, which is a collection of stock of regulation and contains all federal level regulations. $^{7}$ Even though page counts are a fairly good measure of regulation, this measure is subjected to some criticisms. This arises from the fact that each page is different from the others in terms of significance to the economy in regulatory aspect. Each page might not be equally restrictive, some of the pages might be important

\footnotetext{
${ }^{7} \mathrm{CFR}$ is based on a complementary document called the Federal Register which is an official record of rules, proposed rules, notices of federal agencies and various executive orders and documents. Reg Data focuses on CFR instead of the Federal Register. The Federal Register often contains documents, like notices about future rules, which are related to regulations but are not necessarily binding.
} 
regarding regulatory aspects whereas others might not contribute to rule-making at all. Also the number of page counts of CFR does not reflect the applicability of the associated regulation to the industry. Furthermore, change in formatting guidelines might lead to disparity in regulation measure based on page count. Furthermore, some CFR titles give more importance to maps, diagrams and tables and do not use as much text. In the latter case, page count might not have same regulatory implications across all the titles.

In order to overcome the above mentioned shortcomings, Al-Ubaydli and McLaughlin (2017) created Reg Data, which uses text analysis to count the number of times words like "shall", "must", "may not", "prohibited" and "required" occur in each division of the CFR. These five strings act as a measure of binding constraints. They use machine learning program to calculate the number of occurrences of each of these five strings in each division of the CFR published from 1997 to 2012. The total number of times these strings occur in the CFR division is considered as the total number of restrictions because these are used to restrict legal choices. Another method used by Reg Data for measuring regulation is counting the total number of words occurring annually in the CFR. However, the correlation between total restrictions and total annual word count is very high around 0.96.

CFR is divided into 50 titles, each corresponding to a broad subject area under federal regulation. For example, Title 1 covers General Provisions and has 44,000 words whereas Title 7 covers Agriculture containing 6,100,000 words. However, none of the divisions of the CFR corresponds to an specific narrow industry. There is no such rule that owner of a ship has to comply by only the regulations associated to Title 46 (Shipping), rather he has to comply by all the restrictions associated with titles relevant to his firm, like Title 33 (Navigation and Navigable Waters) and Title 49 (Transportation). RegData contains data broken down to every division under CFR. The data ranges from broad division such as Title, which reports broad subject area of regulations, to finer division such as Paragraph containing detailed regulatory requirements. 
Even though Reg Data is comparatively new, a number of papers have utilized it already. Given Reg Data is a novel dataset which measures federal regulation at the industry level, it can be used to analyze effect of regulation on different outcome variables like entrepreneurial activities, employment etc., across different industries. Goldschlag and Tabarrok (2014) use RegData to answer the question to what extent federal regulation is responsible for declining trends in entrepreneurial activities and economic dynamism. Coffey et al. (2016) estimate the effects of federal regulation on value added to GDP for 22 industries and conclude that economic growth has reduced by 0.8 percent yearly due to strict federal regulation. Carboni et al. (2017) find that after the passage of Dodd Frank Wall Street Reform and Consumer's Protection Act the affected companies became more enthusiastic to hire former politicians as directors which provides evidence in favor of existence of a causal relation between industry-level regulation and political connections.

Reg Data uses text analysis in order to measure applicability of the regulations contained in each division in CFR to specific industry. There is no one-to one mapping from CFR to the North American Industry Classification System(NAICS) code on the basis of title name. ${ }^{8}$ In order to convert the NAICS code into search strings a collection of strings are created for each NAICS code denoting a particular industry. Then the total number of occurrences of the search strings for each division of CFR are calculated to create industry-specific relevance. Using regulations contained in each unit of CFR and the industry relevance of the regulation Al-Ubaydli and McLaughlin (2017) creates the industry regulation index which is used for this paper. Reg Data $\left(r_{y i}\right)$ is a panel variable which measures regulation for I (depending on whether NAICS code is at two digit, three digit or 4-digit level) industries and $\mathrm{Y}$ years running from $1997-2012 .^{9}$

\footnotetext{
${ }^{8}$ The North American Industry Classification System (NAICS) is the standard used by Federal statistical agencies for classifying industries. NAICS was developed by Office of Management and Budget (OMB) and was adopted in 1997 to replace Standard Industrial code classification (SIC).

${ }^{9}$ See Al-Ubaydli and McLaughlin (2017) for more details.
} 


\subsubsection{Controls}

The controls I have included in this paper follow the empirical entrepreneurship literature using KFS data (Robb and Robinson, 2014; Cole and Sokolyk, 2013; Gai and Minniti, 2015). Table 2.1 shows the summary statistics for the key variables used in the analysis. I have included total employees, total asset, credit risk, total debt, gender, education of the owner, work experience of the primary owner and whether the primary owner is a white as variables. The variables total asset represents asset values of the firm, including total asset cash and total asset equipment. The data shows at the end of survey year 201158.8 percent of the total sample of firm continues to operate while 41.2 percent of the sample firm has exited the market through the time period from 2004 to 2011. The variable of interest, industry regulation index shows a considerable amount of variation with a mean value of $6,871,439$. A firm belonging to Mining Industry shows the maximum value for industry regulation index which is $23,700,000$. The average value of total asset is $\$ 785,166.30$ and the maximum value is $\$ 10,000,000$. I have divided total number of employees (both full and part time employees) hired by the firm, into two groups, firms with employees less than 100 fall under small size group whereas firms with more than 100 employees fall under large sized group. On an average 67 percent of the sample is white and 74 percent of the businesses are owned by male owners.

Figure 2.1 provides some evidence in favor of higher exit rate of small sized firms compared to large size firms, with increasing regulation. On the vertical axis I plot the exit rates of firms for the time period 2004-2011 and on the horizontal axis, I plot the changes in regulation over the same time period. As expected the small firm's exhibit higher exit rates compared to the exit rate of small sized firms. The exit rate of small firms is almost twice when the regulation is relatively higher whereas the comparatively large sized firms, that is, those who have more than 100 employees are more prone to be in the market as the regulation increases. ${ }^{10}$

\footnotetext{
${ }^{10}$ Any value higher than average value of regulation is considered as high regulation.
} 


\subsection{Empirical Model}

This paper explores the effect of industry specific regulation on the firm's decision to exit the market using an unbalanced pane ${ }^{11}$ data of $4928^{12}$ firms over the time period of 2004-2011. The empirical model is specified as follows:

$$
\begin{aligned}
& \text { Event }_{i t}=\alpha+\beta_{1} \text { IndustryRegulationIndex }_{i t}+ \\
& \beta_{2} \text { IndustryRegulationIndex }_{i t} \times \text { largesize }+\beta_{3} \text { year }_{t}+\varepsilon_{i t}
\end{aligned}
$$

where i denotes industry and t denotes time. The survival analysis is designed in a way such that the Event occurs if the firm exits the market, based on the data from Kauffman Firm Survey. Industry regulation index is an indicator of the intensity of regulation for a particular industry and data for regulatory index has been taken from RegData and Year t represents year dummies. Controls include total employees, total debt, credit risk, total asset and total equity and various owner characteristics including race, education and gender of the primary owner. As the dependent variable is binary, I utilize a hazard model, specifically Weibull and Cox hazard models including industry and time fixed effects. If, according to my hypothesis, firm regulation accentuates firm exit, the expected value of $\beta_{1}$ will be more than 1 . That is, if the regulation is more restrictive the firm is less likely to leave the market. I also perform a survival analysis for the firms which opted for mergers and acquisitions.

$$
\begin{aligned}
\text { Event }_{i t} & =\alpha+\beta_{1} \text { StateRegulationIndex }_{i t}+\beta_{2} \text { StateRegulation }_{i t} \times \text { largesize } \\
& +\beta_{3} \text { year }_{t}+\varepsilon_{i t}
\end{aligned}
$$

Next, in order to investigate whether a comparatively large firm has an advantage

\footnotetext{
${ }^{11}$ The firms leave the market at any point of time throughout the duration of survey years from 2004 to 2011. Once the firm leave the market, it is excluded from the data, that is, as the firm leave the market there is no chance of the firm restarting the business. As the number of firms do not remain same across the time of 8 years, the data used for analysis is unbalanced panel data.

${ }^{12}$ The regulation data from Reg Data is not available for industries like Accommodation and Food Services (NAICS CODE 72), Management of Companies and Enterprises (NAICS CODE 55), Retail Trade(NAICS CODE 44-45), Transportation and Warehousing (NAICS CODE 48-45). Hence, I lose information regarding some firm from KFS data belonging to above mentioned classification.
} 
over comparatively smaller firm, I create dummies for employee size more than 100 and my base level is employee size 1-100 (Calcagno and Sobel, 2014). Now for each dummy variable I create respective interaction terms by multiplying the total employees to the industry regulation. As for example, for dummy denoting employees more than 100, I create an interaction term by multiplying actual number of employees denoted by the employee size with the regulation index. Now, in order to verify whether regulation has different impacts on small firms compared to large firms, I run regression with respective interaction terms denoting various sizes of the firm. Calcagno and Sobel (2014) using state level regulation concluded that increasing regulation reduces the number of firms having small number of employees (less than 100) compared to the firms having larger employee size (more than 100). Klapper et al. (2006) argues in the same line stating that high market level entry regulation only allows comparatively larger firms to enter the market while hampering creation of new firms with small sizes. I repeat the regression analysis with state level regulation. I have used data for state-level expenditures on regulatory inspection and enforcement per capita, taken from the US Census data on State and Local Government Finances, for measuring state-level regulation.

Next, I look at the effect of state regulation on firm survival rate and how it varies with size. Following Calcagno and Sobel (2014), I use state regulation to check whether stricter state regulation might affect firm exit rate. However, one problem with using state level regulation data is that the rest of the variables including the outcome variable is at the firm level. In order to overcome this problem, I have used the method used by Klapper et al. (2006). I have interacted the state regulation variable with a firm level characteristic, that is, whether a firm is a high technology firm.

In this paper, I have used survival analysis or hazard models. There is a problem in terms of using pooled OLS or logistic regression method in case of this particular data due to the fact that there is asymmetry in terms of duration of firms in the market. OLS or logistic regression analysis will fail to compute the survival time of a 
particular firm in the market. The problem of using logistic model, except from the fact that it would fail to account for the survival time of the firm in the market, is that logistic regression would consider each and every observation to be independent. But in reality, a firm which survives the first year of survey reoccurs in the second year. The problem for using OLS is due one of basic assumption the normality, that is, normality of errors. This might not be true always in case this case. Under the normality assumption any event has a constant probability of occurrence whereas in case of survival data any event has instantaneous risk of occurrence. One way to address the above problem is to use survival analysis where the main purpose is to observe the time until attrition. Survival analysis can measure the respective time until the event happens for the different subjects who experience the outcome at various time periods. Moreover, censoring is a very common phenomenon in case of survival data. OLS models often fail to take account of the difference between censored and uncensored data.

Censoring is a common problem which arises in case of survival data. The event of interest in this particular case is firm exiting the market (event=1, the firm has permanently exited the market; 0 , the firm has successfully survived the duration of survey). However right censoring of the data occurs when the firm temporarily leaves the market before the closure occurs. Following Coleman et al. (2010) if the reason for temporarily exit of the market is unknown or in other words it is 'non-informative' censoring, ignoring those observations might be problematic for the analysis. I have accounted for the censored data for survival analysis by accounting for the firms who opted for mergers and acquisition and there is not any significant change in results.

In this paper, I have used both parametric and semi-parametric modeling for hazard models. The benefit for using a semi-parametric analysis over a parametric one is semi-parametric models do not require assumption of any particular distribution function for the survival time unlike parametric models. 


\subsubsection{Parametric model}

Let $\mathrm{T}$ denote a continuous non-negative random variable representing survival time. Let probability density function (pdf) be $\mathrm{f}(\mathrm{t})$ and cumulative distributive function (cdf) $F(t)=\operatorname{Pr}\{T \leq t\}$. Let the survival function be $\mathrm{S}(\mathrm{t})=\operatorname{Pr}\{\mathrm{T}>\mathrm{t}\}$, the probability of being in the market at $\mathrm{t}$ and the hazard function is defined as $\lambda(t)=$ $\mathrm{f}(\mathrm{t}) / \mathrm{S}(\mathrm{t})$.

Now let $\phi(t)=\int_{0}^{l} \lambda(u) d(u)$, where $\lambda(u) d u$ denotes the cumulative hazard. Assume that $\mathrm{S}(\mathrm{t})=\exp \{-\phi(\mathrm{t})\}$. Any distribution defined on $\mathrm{t} \epsilon[0, \infty)$ can act as a survival function. Assuming that the survival time follows parametric form, Weibull, Exponential and log-logistic are few examples of distribution that survival function follows. In this case, I am expressing the survival model in terms of Weibull distribution even though the other parametric distributions more or less yield same result.

Assuming, $\mathrm{T} \sim$ Weibull $(\lambda, \mathrm{p})$ with probability density function $\mathrm{F}(\mathrm{t})=\lambda p t^{p-1} \exp \left(-\lambda t^{p}\right)$. where $\mathrm{p}>0$ and $\lambda>0$, the hazard function is given by $\lambda(t)=\lambda p t^{p-1}$, where $\mathrm{p}$ is called the shape parameter which is fixed for parametric models.

For my analysis, I only consider the data for start-up firms. The firms which leave the market each year has been referred as failure. The variable status denotes whether the firm is in the market for every year starting from 2005 to 2011 . The variable takes the value 1 if the firm exits the market and 0 otherwise. The survival time denotes the time until the firm drops out of the market. As for example, 172 firms exited the market in 2005 which is 5.5 percent of the total firms in the market at the starting of 2005. For these 172 firms the survival time is 1 year.

An alternative approach to model survival data is to assume that the hazard can be increased or decreased by proportionate amount at all time periods. Reparametrizing $\lambda$ by $\lambda=\exp \left(\beta_{0}+\beta_{1}\right.$ Event $)$, the hazard ratio is calculated (Event=1 vs. Event=0) as $H R=\frac{\exp \left(\beta_{0}+\beta_{1}\right) p t^{p-1}}{\exp \left(\beta_{0} p t^{p-1}\right)}=\exp \left(\beta_{1}\right)^{13}$ The hazard ratio is mainly used to compare the hazard rate between two groups, a group which has exited the market (denoted by

\footnotetext{
${ }^{13}$ The validity of the $\mathrm{HR}$ ratio is contingent upon the fact that $\mathrm{p}$ has same value for event=1 vs. event $=0$ which is the case in case of Weibull distribution as $\mathrm{p}$ is constant.
} 
Event $=1$ ) compared to those who are in in the market (denoted by Event $=0$ ). A hazard ratio of value 1 indicates that there is no difference between the two groups, whereas a hazard ratio less than 1 indicates that the effect of an event is lesser for the group which has exited the market compared to the one who is still in the market.

\subsubsection{Semi parametric model}

The advantage of using asemi-parametric model, like the Cox proportional hazard model is the baseline hazard function is unspecified. Moreover, the distribution of the survival time is unknown. The cox proportional hazard models provide estimates of hazard rates close to the parametric models with minimum assumptions. Let the hazard function be $\mathrm{h}(\mathrm{t} \mid$ xit $)=\mathrm{h} 0(\mathrm{t}) \exp (\operatorname{xit} \beta)$, where $\mathrm{h}(\mathrm{t} \mid$ xit $)$ is the hazard rate which describes the probability that the firm will survive at time $t$ given the fact that the firm has survived up to the time $\mathrm{t}-1 . \mathrm{h} 0(\mathrm{t})$ is the baseline hazard rate and $\mathrm{xit} \beta$ is the linear function of the explanatory variables and does not include time. If $\beta$ is equal to zero the hazard ratios of the two groups are same in terms of survival time. Thus, the hazard function describe the relationship between firms' survival (hazard rate) and time, and various owner's and firm's attributes.

Some of the covariates that I have used like owner's attributes, gender, citizenship etc. are time invariant variables whereas my main variable of interest industry regulation index varies over time. Therefore, I have used a mixed Cox model using both time-varying and time invariant variables. Let the hazard function in the Cox mixed model be $\mathrm{h}(\mathrm{t} \mid \mathrm{xit})=\mathrm{h} 0(\mathrm{t}) \exp \left(\mathrm{xi} \beta_{0}+\mathrm{xjt} \beta_{1}\right)\left(\right.$ McKeague and Sasieni, 1994), where $\beta_{0}$ reports the coefficient of time invariant covariates and $\beta_{1}$ reports the coefficient of time-varying covariates. Following Gai and Minniti (2015), I use survival panel model to investigate the effect of time varying and time invariant covariates on firm survival. 


\subsection{Results}

The objective of the paper is to analyze the effect of industry wise regulation data on firm's exit. The goal is also to identify whether effect of industry specific federal regulation on firm's exit differs by size. Due to the asymmetry in firm's duration in the market I have used survival analysis.

Table 2.3 shows the hazard ratios from the Cox hazard models and Weibull Model (Column 1 and 2 respectively). Table 2.4 reports the effect of regulation on mergers and acquisitions. In order to test whether regulation affects firm's exit decision differently based on firm's size, I include interaction terms between the number of employees and the industry regulation for employment size more than 100 . The results confirm my argument that small firms are more likely to exit with higher regulation. Table 2.4 includes the survival analysis including the interaction terms between employees and industry level federal regulation for the firms who did not exit the market but went through mergers. Table 2.5 includes the interaction terms between state regulation and number of employees for high (more than 100 employees) and low (less than 100 employees) employee size. The results for Weibull and Cox Proportional hazard models are reported in terms of hazard ratios. A hazard ratio greater than 1 indicates higher probability of the event to occur which in this case implies that higher risk of exiting the market.

Both Table 2.3 and Table 2.4 show that with increasing federal regulation the probability of exit and merger increases respectively. The magnitude of effect of industry level federal regulation on overall firm exit is very negligible. Column 1 reports the hazard ratios from Cox Hazard Distribution and Column 2 reports the result from Weibull regression. In Table 2.3, with increasing regulation the hazard ratio increases by 2.2 percent implying that, with higher regulation the firms are 2.2 percent more likely to exit the market. As regulation increases the large firms are 0.9 percent less likely to exit the market compared to small firm. Industry level federal regulation has significant effect for firms having employee size more than 100. As the 
industry level regulation increases firms with the employee size more than 100 are more probable to be in the market compared to the firms having employees less than 100. Table 2.4 also shows that the firms having more than 100 employees are less likely to opt for mergers compared to the firms having less than 100 employees.

With higher credit risks the firms are 32 percent more likely to leave the market. The survival models also show that with higher education levels, the firms experience lower hazard rate of closure. All else equal, owners with higher education levels are less likely to sell their own business. I also find that firms having primary owners with higher work experience firms have higher survival rates. This result is in line with the existing literature (Coleman et al., 2013) arguing that human capital has positive impact on firm closure. Additionally, the results show that white owners are 9.89 percent more likely to be in the market. These results are also consistent with the findings of Gai and Minniti (2015) and Fairlie and Robb (2007). Gai and Minniti (2015) have suggested that there is a gap in survival rate of black and white owned business which is explained partly by the lack of availability of credit for the black owned business. However, unlike Coleman et al. (2013) I did not find any significant effect of age of primary owner on the survival rate. However, firms with higher total assets are more likely to survive for a longer time whereas firms with lower debt are more likely to leave the market early.

Table 2.5 reports the survival analysis using state level regulation. The result shows that like industry level federal regulation, as state regulation increases there is a overall 1.23 percent more chances of the firms to be in the market. The firms with employee size 100 are 2.2 percent more likely to be in the market with higher state regulation. This result is consistent with effect of industry level regulation. Also unlike previous results age of owner has a significant influence on firm exit. As age of the owner increases, the firms are more likely to survive for a longer time. Additionally, credit risk and total debt have negative effects whereas total sales, total assets have positive impact on firm survival.

Comparing the magnitude of effect of state regulation and industry level federal 
regulation, I find that the magnitude of effect of federal regulation is higher on bigger size firms. Even though the difference in magnitude is negligible, industry level federal regulation provides higher comparative advantage compared to the large firms. As federal regulation increases the likelihood of the large firms to be in the market increases.

\subsection{Conclusion}

The existing studies take the help of neo classical theory to explain the effect of regulation on firm, arguing that regulation acts as a fixed cost. Higher regulation piles up on the firm's fixed cost inducing it to leave the market. On the other hand, scale of operation is also a major factor in terms of firm's exit decision. A firm with higher scale of operation can exploit the economies of scale thereby reducing the per unit fixed cost, the industry specific regulation in this case. On the contrary, a firm which has small scale of operation has to comply by higher regulatory burden increasing its probability to leave the market. The firm having comparatively smaller size are more likely to leave the market as the regulatory burden increases due to smaller scale of operation. On the contrary, firms having higher size enjoy a comparative advantage and prefer stricter regulation (Klapper et al., 2006).

My findings are also consistent with the findings of Bailey and Thomas (2015). They, using Reg Data for the period of 1998-2011, concluded that large firms are less likely to die when the level of regulation increases. Moreover, Calcagno and Sobel (2014) argue that regulation acts as a fixed cost and reduces the number of small firms whereas the large firms easily comply to the higher regulation, given their large scale of operation. To summarize, using firm level data from Kauffman Firm Survey and federal regulation data from Reg Data and state regulation data from U.S Census, I find that stricter regulation influences smaller sized firms to leave the market whereas the large firms enjoy comparative advantage due to economies of scale, and prefers strict regulation. 
Sriparna Ghosh

Table 2.1: Summary Statistics

\begin{tabular}{lrrrrr}
\hline \multicolumn{1}{c}{ Variable } & Observations & \multicolumn{1}{c}{ Mean } & St. Dev. & Min & \multicolumn{1}{c}{ Max } \\
\hline Industry regulation & 11,932 & $6,871,439$ & $6,073,104$ & 517,365 & $23,700,000$ \\
State regulation & 11,932 & 65 & 128.570 & 50 & 3427.19 \\
Credit risk & 11932 & 2.968 & 0.893 & 1 & 5 \\
Total debt $(\$)$ & 11,932 & $56,566.304$ & $67,505.417$ & 170 & $25,000,000$ \\
Total equity $(\$)$ & 11,932 & $30,692.450$ & 939,859 & 100 & $9,000,000$ \\
Total revenue $(\$)$ & 11,932 & $785,166.300$ & & 0 & $5,743,000$ \\
Total asset (\$) & 11,932 & $785,166.300$ & $6,094,726$ & 275 & $10,000,000$ \\
Work experience of primary owner & 1,1932 & 14.234 & 10.776 & 0 & 50 \\
Age of primary owner & 11,932 & 46 & 10.850 & 17 & 87 \\
Primary owner white & 11,932 & 0.671 & 0.470 & 0 & 1 \\
Education of primary owner & 11,932 & 6.841 & 1.985 & 1 & 10 \\
Gender of primary owner & 1,1932 & 0.757 & 0.429 & 0 & 1 \\
Employment high & 1,000 & 150 & 93.394 & 100 & 265 \\
Employment low & 10,932 & 15 & 4.430 & 10 & 100 \\
\hline
\end{tabular}

Note: Time Period: 2004-2011 
Table 2.2: Status of the firm by year

\begin{tabular}{lrr}
\hline Year & Firms exited the market & Firms in the market \\
\hline 2004 & 0 & 3,126 \\
2005 & 172 & 2,954 \\
& 5.5 & 94.5 \\
2006 & 199 & 2,755 \\
& 6.36 & 88.13 \\
2007 & 202 & 2,553 \\
& 6.46 & 81.67 \\
2008 & 232 & 2,321 \\
& 7.4 & 74.25 \\
2009 & 164 & 2,157 \\
& 5.24 & 69.00 \\
2010 & 165 & 1,992 \\
& 5.28 & 63.72 \\
2011 & 153 & 1,839 \\
& 4.89 & 58.83 \\
\hline
\end{tabular}

Note: Time period 2004-2011 
Sriparna Ghosh

Table 2.3: Survival Analysis

\begin{tabular}{lrr}
\hline \multicolumn{1}{c}{ Variable } & Cox Regression & Weibull distribution \\
\hline Industry regulation & $1.022^{* *}$ & $1.021^{* * *}$ \\
& $(0.001)$ & $(0.023)$ \\
Employees more than $100^{*}$ industry regulation & $0.991^{* * *}$ & $0.996^{* * *}$ \\
& $(0.002)$ & $(0.001)$ \\
Credit risk & $1.322^{* * *}$ & $1.301^{* * *}$ \\
& $(0.031)$ & $(0.011)$ \\
Total debt & $1.210 * *$ & $1.121^{* *}$ \\
& $(0.001)$ & $(0.002)$ \\
Total asset & 0.976 & 0.991 \\
& $(0.003)$ & $(0.002)$ \\
Total revenue & $0.925^{* * *}$ & $0.922^{* * *}$ \\
& $(0.006)$ & $(0.015)$ \\
Work experience & $0.985^{* * *}$ & $0.988^{* * *}$ \\
& $(0.002)$ & $(0.001)$ \\
Age of primary owner & $1.011^{* * *}$ & $1.112^{* * *}$ \\
& $(0.001)$ & $(0.008)$ \\
Primary owner white & $0.811^{* * *}$ & $0.9734^{* * *}$ \\
Education of primary owner & $(0.105)$ & $(0.116)$ \\
Gender of primary owner & $0.940^{* *}$ & $0.938^{* * *}$ \\
& $(0.010)$ & $(0.015)$ \\
Year fixed effects & $0.766^{*}$ & $0.757^{*}$ \\
Observations & $(0.048)$ & $(0.041)$ \\
Pald Chisq $>$ Wald Chisq & Yes & 11,932 \\
\hline Note: Des & 12.13 \\
& 11,932 & 0.00 \\
\hline
\end{tabular}

Note: Dependent variable Event $=1$ if the firm exits the market, 0 if the firm survives. Robust Standard errors in parentheses. ${ }^{* * *} \mathrm{p}<0.01,{ }^{* *} \mathrm{p}<0.05,{ }^{*} \mathrm{p}<0.1$ 
Sriparna Ghosh

Table 2.4: Survival Analysis for merger and acquisition

\begin{tabular}{lrr}
\hline \multicolumn{1}{c}{ Variable } & Cox Regression & Weibull distribution \\
\hline industry regulation & $1.011^{* *}$ & $1.012^{* *}$ \\
& $(0.008)$ & $(0.007)$ \\
Employees more than $100^{*}$ industry regulation & $0.916^{* * *}$ & $0.946^{* *}$ \\
Credit risk & $(0.012)$ & $(0.022)$ \\
& $1.021^{* *}$ & $1.011^{* *}$ \\
Total debt & $(0.011)$ & $(0.010)$ \\
& $1.210^{* *}$ & $1.221^{* *}$ \\
Total asset & $(0.001)$ & $(0.012)$ \\
& 0.976 & 0.955 \\
Total revenue & $(0.003)$ & $(0.002)$ \\
& $0.915^{* * *}$ & $0.923^{* * *}$ \\
Work experience of primary owner & $(0.006)$ & $(0.001)$ \\
& $0.985^{* * *}$ & $0.977^{* *}$ \\
Age of primary owner & $(0.002)$ & $(0.001)$ \\
& $0.950^{* * *}$ & $0.943^{* * *}$ \\
Primary owner white & $(0.112)$ & $(0.021)$ \\
Education of primary owner & $0.851^{* * *}$ & $0.844^{* * *}$ \\
Gender of primary owner & $(0.105)$ & $(0.121)$ \\
& $0.940^{* *}$ & $0.931^{* *}$ \\
Year fixed effects & $(0.010)$ & $(0.021)$ \\
Waservations & $0.750^{* * *}$ & $0.757^{* * *}$ \\
Prob Chisq $>$ Wald Chisq & $(0.048)$ & $(0.033)$ \\
\hline Note: Deps & Yes \\
& 437.00 \\
& 44.05 & 0.00 \\
\hline
\end{tabular}

Note: Dependent variable Event $=1$ if the firm exits the market or merge and acquisition happens, 0 if the firm survives. Robust Standard errors in parentheses. $* * * \mathrm{p}<0.01,{ }^{* *} \mathrm{p}<0.05, *$ $\mathrm{p}<0.1$ 
Sriparna Ghosh

Table 2.5: Survival Analysis with state regulation

\begin{tabular}{|c|c|c|}
\hline Variable & Cox Regression & Weibull distribution \\
\hline \multirow[t]{2}{*}{ State regulation } & $1.001^{*}$ & $1.001^{*}$ \\
\hline & $(0.001)$ & $(0.011)$ \\
\hline \multirow[t]{2}{*}{ State regulation index* more than 100 employees } & $0.978 * * *$ & $0.977^{* * *}$ \\
\hline & $(0.001)$ & $(0.008)$ \\
\hline \multirow[t]{2}{*}{ Credit risk } & $1.100^{* * *}$ & $1.101^{* * *}$ \\
\hline & $(0.001)$ & $(0.018)$ \\
\hline \multirow[t]{2}{*}{ Primary owner white } & $0.996^{* *}$ & $0.995^{* *}$ \\
\hline & $(0.121)$ & $(0.004)$ \\
\hline \multirow[t]{2}{*}{ Education } & $0.954^{*}$ & $0.958^{*}$ \\
\hline & $(0.121)$ & $(0.017)$ \\
\hline \multirow[t]{2}{*}{ Gender } & 0.946 & 0.946 \\
\hline & $(0.276)$ & $(0.007)$ \\
\hline \multirow[t]{2}{*}{ Age of primary owner } & $0.980^{*}$ & $0.979 *$ \\
\hline & $(0.011)$ & $(0.004)$ \\
\hline \multirow[t]{2}{*}{ Total assets } & $0.996^{* * *}$ & $0.998^{* * *}$ \\
\hline & $(0.011)$ & $(0.001)$ \\
\hline \multirow[t]{2}{*}{ Total debt } & $1.001^{* *}$ & $1.001^{* *}$ \\
\hline & $(0.005)$ & $(0.001)$ \\
\hline Year fixed effects & Yes & Yes \\
\hline Observations & 11,932 & 11,932 \\
\hline Wald Chisq & 13.12 & 12.45 \\
\hline Prob > Wald Chisq & 0.00 & 0.00 \\
\hline
\end{tabular}

Note: Dependent variable Event $=1$ if the firm exits the market, 0 if the firm survives. Robust Standard errors in parentheses. ${ }^{* * *} \mathrm{p} \mathrm{i} 0.01,{ }^{* *} \mathrm{p}<0.05,{ }^{*} \mathrm{p}<0.1$ 
Table 2.6: Description of variables

\begin{tabular}{|c|c|}
\hline Variable & Description \\
\hline Industry regulation & $\begin{array}{l}\text { Number of restrictive words per } 4 \text { digit } \\
\text { NAICS code }\end{array}$ \\
\hline State regulation & $\begin{array}{l}\text { state-level expenditures on regulatory } \\
\text { inspection and enforcement per capita }\end{array}$ \\
\hline Credit score & $\begin{array}{l}\text { Credit risk class ranging from } 1 \text { to } 5 \\
\text { based on high to low credit score re- } \\
\text { spectively }\end{array}$ \\
\hline Total employee & total full and part time employees \\
\hline White & $\begin{array}{l}\text { whether the primary owner is } \\
\text { white }(=1)\end{array}$ \\
\hline $\begin{array}{l}\text { Education of primary } \\
\text { owner }\end{array}$ & $\begin{array}{l}\text { Education level of primary owner rang- } \\
\text { ing from } 1 \text { (=less than } 9 \text { th grade) to } 10 \\
\text { (professional school or doctorate) }\end{array}$ \\
\hline Gender & $\begin{array}{l}\text { whether the primary owner is male }=1 \text {, } \\
0 \text { otherwise }\end{array}$ \\
\hline $\begin{array}{l}\text { Work experience of pri- } \\
\text { mary owner }\end{array}$ & $\begin{array}{l}\text { Primary owner's work experience in } \\
\text { years }\end{array}$ \\
\hline Total assets & Total asset values \\
\hline Total debt & Total value of the debt \\
\hline
\end{tabular}

Note: Dependent variable Event $=1$ if the firm exits the market, 0 if the firm survives. Robust Standard errors in parentheses. ${ }^{* * *} \mathrm{p} i 0.01,{ }^{* *} \mathrm{p}<0.05,{ }^{*} \mathrm{p}<0.1$ 


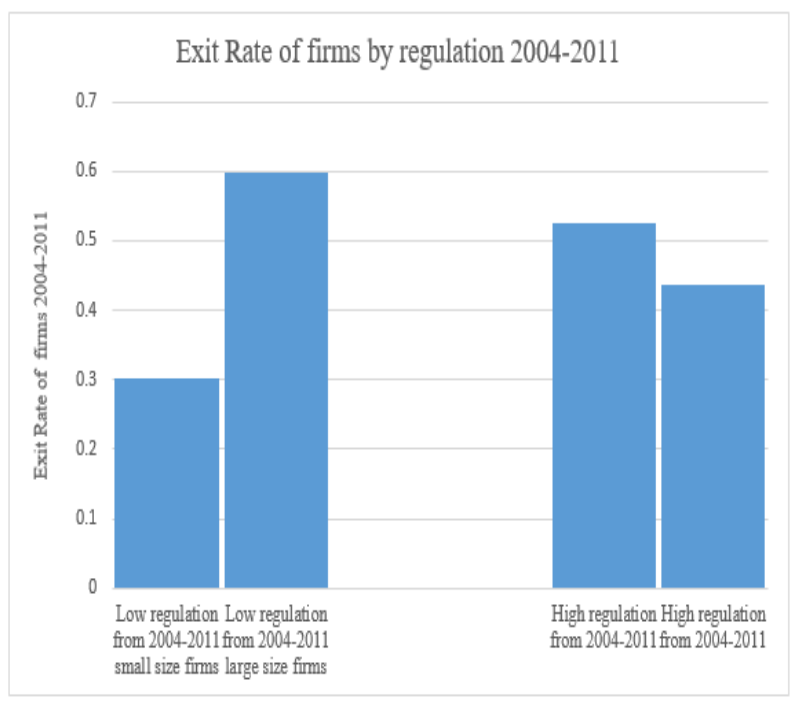

Figure 2.1: Exit Rates of firms by Regulation 


\section{Chapter 3}

\section{Regulation and Entrepreneurial Intention}

Entrepreneurship is one of the driving forces of economic growth in a country (Reynolds et al., 1999; Berkowitz and DeJong, 2005; Kreft and Sobel, 2005). The differences in entrepreneurship rates accounts for almost $50 \%$ of the difference in economic growth of a country (Zacharakis et al., 2000). On the other hand, economic freedom is a major determinant of economic growth across countries (Gwartney et al., 1999). Linking these concepts, Ovaska et al. (2005) and Kreft and Sobel (2005) deduced that economic freedom fosters economic growth via entrepreneurial activity. According to the Business and Industry Advisory Committee to the Organization for Economic Cooperation and Development (OECD), "Policies to foster entrepreneurship are essential to job creation and economic growth."

Only a handful of studies have looked at the linkage between economic freedom and entrepreneurship (Nyström, 2008; Bjørnskov and Foss, 2010; Angulo-Guerrero et al., 2017; Carlos Díaz-Casero et al., 2012). Bjørnskov and Foss (2010) made a concerted effort to explain cross-country differences in entrepreneurship with the help of changes in economic policies and institutional framework. They used data for Total Early Stage Entrepreneur (TEA) from Global Entrepreneurship Monitor (GEM) for the year 2001 for 29 countries as a measure of entrepreneurship. They obtained 
Economic Freedom Index data from the Fraser Institute. TEA is a measure of the percentage of individuals, between the ages of 18 and 64, who are either nascent entrepreneurs or owners of new businesses. Nyström (2008), on the other hand, verified the relationship between economic freedom and entrepreneurship in a panel data setting. In her study, she used self-employment rates from the COMPENDIA database for 23 OECD member countries (from 1972-2002) as the measure of entrepreneurship, and the economic freedom index data from Fraser Institute. Sobel et al. (2007) verified the relationship between entrepreneurial activity, measured by TEA, and the economic freedom for OECD countries in 2002. Angulo-Guerrero et al. (2017) analyzed the effect of economic freedom on necessity and opportunity entrepreneurship by using data for OECD countries for the time period 2001-2012. Carlos Díaz-Casero et al. (2012) using data GEM data for 2002 to 2009, investigated the relationship between economic freedom and entrepreneurial activity for the innovation driven economies. In summary, there is a clear gap in the literature regarding a comprehensive examination of the effects of economic freedom on entrepreneurial activity. The few studies that do look into the matter use data that are either for a single year or for a limited set of countries (Sobel et al., 2007; Nyström, 2008; Bjørnskov and Foss, 2010; Angulo-Guerrero et al., 2017; Carlos Díaz-Casero et al., 2012).

While most studies focus on entrepreneurial activity, it is interesting to verify the determinants of various individual attributes, for example entrepreneurial intention. Recently, research regarding latent entrepreneurship has become a topic of interest for many researchers. This interest is largely due to the fact that entrepreneurship has become a major channel, via job creation, for improving the economy. The extant literature has examined the driving factors that influence entrepreneurial intention. A study conducted in France shows that the external entrepreneurial environment and enforced learning (through entrepreneurial courses and seminars) influence the attitude of management and engineering students towards new business creation (Klapper and Leger-Jarniou, 2006). A similar study in Malaysia indicates that attending entrepreneurship courses motivates management students to become entrepreneurs 
(Zain et al., 2010; Ariff et al., 2010). Gohmann (2012) focuses on the role of institutions regarding latent entrepreneurship (measured, over 18 countries, via corruption and economic freedom). However, these are all small-scale studies that use survey data. None of these papers investigate the relationship between economic freedom, specifically regulation and entrepreneurial intention.

The influence of the external environment (e.g., regulatory environment, ease of investment, etc.) also plays a key role in the creation of entrepreneurs within a country (Ardagna and Lusardi, 2008). Developing economies such as India, Singapore, etc., are already showing signs of adapting themselves to this changing environment by removing regulatory roadblocks. Evidently, the regulatory environment of a country majorly affects an individual's decision to start a business. According to Steve Strauss, the renowned lawyer and author who specializes in entrepreneurship, "The simpler and more expedited the regulatory process, the greater the likelihood of small business expansion." Few studies have investigated the effects of regulation on entrepreneurship (Ardagna and Lusardi, 2008, 2009; Van Stel et al., 2007; Bjørnskov and Foss, 2010; Nyström, 2008; Capelleras et al., 2008). Some have investigated the effects of economic freedom on entrepreneurship and they have concluded that better government promotes more entrepreneurship (Bjørnskov and Foss, 2010). At the same time, less stringent regulations on credit, business and labor, are also conducive to entrepreneurship (Nyström, 2008; Capelleras et al., 2008). However, Capelleras et al. (2008) investigated the effect of regulatory framework on new firm growth in two countries with different regulatory frameworks.

Entrepreneurs play a vital role in terms of job creation and social development. This is especially the case in developing countries where entrepreneurs make a major contribution towards the reduction of poverty and inequality. Public policies should, thereby, be directed towards easing regulatory burdens and to further encourage entrepreneurship. While it is important to understand the effects of institutions on entrepreneurship, it is also extremely important to understand the effects of different regulations on latent entrepreneurs. That is, those who have not yet started 
their businesses but are planning to do so within the next three years. The purpose of this paper is to identify whether institutional qualities act as road blocks towards channeling the unemployed population, within developing countries, towards entrepreneurship. As we will see, they do inhibit entrepreneurship.

This study has a two-fold contribution to the literature. First, whereas most of the literature uses TEA (Total Early-stage Entrepreneurial Activity) or a nascent entrepreneurial rate to measure entrepreneurial activity, I use entrepreneurial intention. Entrepreneurial intention is a measure of latent entrepreneurs - defined as individuals who have not yet started a business, but will do so within three years. Second, this paper investigates the effect of Economic Freedom, specifically regulation, on entrepreneurial intention. This paper, then, attempts to fill the void in the literature by linking the EFW Index to entrepreneurial intention. Using GEM data for measuring entrepreneurial activity and EFW data for regulation, I have analyzed the effects of regulation on entrepreneurial intentions. In this study, I have used panel data for 79 countries from 2001 to 2016.

\subsection{Conceptual Framework}

According to the 2016 GEM Report, people from factor driven economies are more willing to take entrepreneurship as a career compared to those from efficiency and innovation driven economies. The factor driven economies (e.g., African countries, India, Iran etc.) which are rich in unskilled labor, show higher business activity thus, signaling necessity based entrepreneurship. However, efficiency and innovation driven economies show opportunity driven entrepreneurship. The data, coupled with the above argument, shows that entrepreneurial intentions are higher in African economies when compared to North American and European economies. Further, the data shows that African countries have a higher Total Early Stage Entrepreneurship (TEA). This implies that a high percentage of latent entrepreneurs actually take up entrepreneurship as a career choice. Incidentally, data show that some of the develop- 
ing countries have stricter regulation and low entrepreneurial intention. For example, in 2012, Nigeria had an entrepreneurial intention of $90.95 \%$, TEA of $34.99 \%$ and a regulatory measure of 7.3. Ethiopia, on the other hand, had an entrepreneurial intention of $23.84 \%$, TEA of $14.73 \%$ and a regulatory measure of 5.75 . This suggests that both entrepreneurial intentions and entrepreneurial activities in Nigeria are nearly three times the respective values in Ethiopia. Both are developing countries, but the regulatory measure in Nigeria is far less strict than compared to Ethiopia. The question arises, then, whether the stricter regulation in a developing country prevents people from taking entrepreneurship as a career choice. Arguably, developing countries differ in terms of latent and actual entrepreneurs due to a disparity in the institutional qualities.

As the literature suggests, a country's regulatory environment affects its entrepreneurship rate. Using data from the World Bank to measure regulation, Van Stel et al. (2007) found that entry regulations have minimal effect on actual entrepreneurship rates, whereas, labor market regulations and financial market restrictions have much larger impact upon such rates. They used GEM indices to measure entrepreneurial activities. Nyström (2008), using the Economic Freedom of the World Index (EFW) to measure regulation, concluded that less stringent regulation on credit, labor and businesses, facilitates the growth of entrepreneurship. However, she used self-employment data for 23 OECD countries from the COMPENDIA research group. Using GEM data for entrepreneurship, Bjørnskov and Foss (2010) did not find any significant effect regarding any form of regulation (including credit, labor and business) on entrepreneurship rates.

Entrepreneurship is defined as "Any attempt at new business or new venture creation such as self-employment, a new business organization, or the expansion of an existing business by an individual, a team of individuals, or an established business" (Reynolds et al., 1999). The GEM Conceptual Framework provides insights into several individual attributes perception of opportunities, perception of own capabilities to act entrepreneurially, fear of failure, and entrepreneurial intentions - which, in a 
specific context, is defined by entrepreneurship-framework conditions.

A variety of factors determine the levels of entrepreneurship in the country (e.g., the size of government, degree of administrative bureaucracy, tax structure, enforcement of property rights, labor laws, availability of financial capital, etc.) (Bjørnskov and Foss, 2010). Brunetti et al. (1997) argued that in a survey of private sectors labor and safety regulations, taxes and access to financial capital were considered as primary impediments by the entrepreneurs. As some of the previous studies found, these institutional frameworks often play an important role in terms of building latent entrepreneurs. All of the aforementioned factors of the institutional framework (e.g., size of government, property rights, labor and financial regulation) relate to economic freedom.

\subsection{Empirical specification}

The empirical model is specified as follows:

$$
\begin{gathered}
Y_{i t}=\alpha_{0}+\alpha_{1} \text { Regulation }_{i t}+\alpha_{2} \text { SizeofGovernment }_{i t}+\alpha_{3} \text { LegalSystem }_{i t}+ \\
\alpha_{4} \text { SoundMoney }_{i t}+\alpha_{5} \text { Trade }_{i t}+\theta X_{i t}+\varepsilon_{i t}
\end{gathered}
$$

where $\mathrm{y}$ is a measure of entrepreneurial intention; Regulation is a summary index which indicates the conditions in the domestic credit market, labor market restrictions and business activity regulations; Size of Government indicates the degree of government intervention; Legal System is the Legal structure and security of property rights; Sound Money is the access to sound money; Trade is freedom to trade internationally; $\mathrm{X}$ is a matrix of additional controls including GDP per capita (in 2005 US dollars), primary school enrollment, secondary school employment and percentage of employment in agricultural sector; and $\varepsilon$ is the error term. The available data is in panel format; I have run fixed effects, including country fixed effects and year fixed effects. I have also run random effects models. However, the Hausman test confirms that the fixed effects model is the more appropriate model.

The regulation index is a measure of various underlying components, such as credit 
market regulations, labor market regulations and regulation for business activities. I have re-estimated the fixed effects model with the first specification including the various components of regulation.

$$
\begin{aligned}
& Y_{i t}=\alpha_{0}+\alpha_{1} \text { CreditRegulation }_{i t}+\alpha_{2} \text { LaborRegulation }_{i t}+ \\
& \alpha_{3} \text { BusinessRegulation }_{i t}+\alpha_{4} \text { SizeofGovernment }_{i t}+ \\
& \alpha_{5} \text { LegalSystem }_{i t}+\alpha_{6} \text { SoundMoney }_{i t}+\alpha_{7} \text { Trade }_{i t}+\theta X_{i t}+\varepsilon_{i t}
\end{aligned}
$$

Using the panel data format for empirical analysis, I have employed the fixed effects model to take into account the unobservable time invariant country-specific effects and year fixed effects.

\subsection{Data}

The data for the dependent variable came from the Global Entrepreneurship Monitor (GEM). The data for the independent variables was taken from the Economic Freedom of the World Report, by the Fraser Institute. Whereas, the control variables were taken from the World Bank.

\subsubsection{Dependent Variable}

Entrepreneurial intention is the dependent variable used in this paper. Entrepreneurial intention includes the percentage of individuals who are willing to start a business within next three years and excluding those who have already started their business. The data was taken from GEM. It is a frequently used data source for the measure of entrepreneurship. The survey shows that more people intend to start a business in developing countries than compared to those in developed countries. In 2004, for example, the entrepreneurial intention of Peru was $48.25 \%$ - compare that to the entrepreneurial intention of the United States, only $8.03 \%$.

GEM is the world's first comprehensive and internationally executed data collec- 
tion of entrepreneurship. The GEM survey first began in 1999 as a joint initiative between Babson College (USA) and the London Business School (UK). Its aim was to determine why some countries were more entrepreneurial than others? GEM has collected data spanning 17 years (since 1999) and presently covers more than 100 countries. It collects primary data on entrepreneurship and thus it can focus on individual attributes and individual entrepreneurial activity. One of the limitations of GEM survey data, however, is that it fails to differentiate between informal and formal entrepreneurship. Another drawback is that the entrepreneurial measure does not exclude the agricultural sector. But self-employment, a primary measure of entrepreneurship, is a "natural" status employment in the agricultural sector and it is different from the self-employment definition used in non-agricultural industries (Van Stel et al., 2007). Unfortunately, the entrepreneurial intention measure in the GEM Report includes data for the agricultural sector. One way to reduce its bias is to control for the employment in this sector.

\subsubsection{Independent Variable}

The independent variables are the five components of the Economic Freedom of World (EFW) index - size of government, legal system and property rights, access to sound money, freedom to trade internationally, and regulation. The data for the independent variables was taken from the Economic Freedom of the World, published by the Fraser Institute. The EFW index is a summary measure (starting from 1970s) of the institutional qualities of 159 countries. This index measures the extent to which countries encourage voluntary transactions and a market allocation of resources. The rating for each area and sub area is placed on a scale of 0 to 10, with the higher rating signifying more economic freedom. The rating for each major area is an average of the underlying components, which, again, is an average of the underlying sub-components.

Area 1 indicates the size of government. It is a summary measure of four underlying components government consumption, transfers and subsidies, government enterprises and investment, and the top marginal rate. Basically, the size of govern- 
ment is a variable which measures government intervention, with a smaller value for the index indicating a better government. Hong Kong tops the list with a rating of 9.4. Compare this to Norway, it has a rank of 46 and a size of government measure of 3.09 .

Area 2 examines the legal system and property rights of a country. It is a measure of the various judiciary and legal rights; this reflects the legal structure of the country. The underlying components of a legal system are the rule of law, security of property rights, an independent judiciary system, and the effective enforcement of law. This, collectively, summarizes the protective role of the government.

Area 3 is a measure of access to sound money. It reflects the stability of the monetary environment of a country. It is a measure of inflation, money growth, recent inflation and freedom to own foreign currency, and bank accounts. Countries with a high measure of the sound money component possess relatively stable inflation.

Area 4, freedom to trade internationally, emphasizes the different measures that increase the cost of engaging in international trade. This takes into account measures of taxation on international trade, barriers to trade (like tariffs and quotas), size of the trade sector, international capital market controls, etc. All of these measures reflect the various restraints that affect international exchange. A country must have lower tariffs, efficient customs, and various controls on exchange rates in order to score a highly within this area.

Area 5 represents regulation, which is the key variable of interest in this paper. Regulation is a measure of restrictions that impede credit, labor, and product market activities. It includes credit market regulations, labor regulations, and business regulations. The first sub-component reflects domestic credit market conditions. A country which mainly relies upon a private banking system and does not control interest rates receives a higher score in this sub-area. The second component deals with labor market regulations, such as minimum wage restrictions, hiring and firing norms, etc. Countries that rely more on market clearing equilibrium wages rank high in labor regulation. The third component represents business regulation; it is 
comprised of various regulatory restrictions that prevent the entry of a firm into the market. A higher score in this area implies an absence of barriers to entry, resulting in more competitive market. New Zealand, for example, has a rank of 20 with a score of 7.3 for business regulation. Compare this to Mali. It has the score of 6.1 with a ranking of 121. Thus, compared to Mali, New Zealand has a less stringent business regulation and, consequently, it offers more economic freedom. The control variables include Gross Domestic Product per capita (in 2005 dollars), the share of population that is between 15 to 64 years of age, the share of population having a primary and secondary enrollment, Foreign Direct Investment (FDI), market capitalization, percentage of female, percentage of unemployed population and the percentage of agricultural employment. Data for each of these variables have been taken from the World Bank.

\subsection{Results}

Table 3.2 shows the results from the effects of regulation on entrepreneurial intention from a fixed effects models, controlling for country and time fixed effects. Table 3.3 , on the other hand, shows the results from the fixed effects models, controlling for both country and time fixed effects and including all the controls. Table 3.4 is the most expansive model; it controls for employment in the agricultural sector, control variables and, both, country and year fixed effects.

The results are generally consistent for all specifications. Legal system and freedom to trade have statistically significant effects on entrepreneurial intention whereas, the size of government, sound money and overall regulation fail to have a statistically significant effect on entrepreneurial intention. Both credit and labor market regulations, however, are significant in most of the specifications. In Table 3.4, the overall regulation does not have any significant effect on entrepreneurial intention. This result is consistent with the findings of Bjørnskov and Foss (2010). They did not find any significant effect regarding overall regulation on entrepreneurial activity. 
Van Stel et al. (2007) also failed to find any statistical significance involving regulation, especially with business regulation on young and nascent entrepreneurship. Nyström (2008) argued that a possible explanation for why the above studies failed to find any significant relationship between regulation and entrepreneurship was because the regulatory environment comes into play in a later stage of entrepreneurship. However, this study points to an interesting result that only credit and labor market regulations affect an individual's intention to start a business as a career alternative.

Regarding the sign of the coefficients, lower credit market regulations are associated with higher entrepreneurial intentions. Whereas, stricter labor market regulations encourage latent entrepreneurship. These findings are in line with those found by Van Stel et al. (2007) and Capelleras et al. (2008). Explaining in the terms of Van Stel et al. (2007), I argue that some entrepreneurs would be more successful to evade business regulations like bureaucratic burdens. Capital requirements, on the other hand, are unavoidable in most cases (Desai et al., 2003). All of these imply that easy access to a credit market might act as a buffer for an entrepreneur to start a business owing to the easy availability of business capital. Therefore, latent entrepreneurs have to abide by credit regulations, resulting in countries with higher credit market regulations exhibiting lower latent entrepreneurship.

On the other hand, this result shows that more flexible labor regulation is associated with lower latent entrepreneurship. A possible explanation of this is that stringent labor laws restrict the number of job flows within the economy - mainly to industries requiring frequent labor adjustments (Henrekson, 2014). This, in turn, leads to the increase in the rate of latent entrepreneurship. Simultaneously, selfemployed and small firms (under a particular employee size) can evade strict employment protection regulations (Henrekson, 2014). However, the above findings differ from those obtained by Van Stel et al. (2007). They found that flexible hiring and firing costs induced more people to leave a job (due to a lack of security) and start their own business (it was simpler to hire employees due to easier labor regulation). Specification 2 of Table 3.3 suggests that the improvement of credit regulation, by 
1 standard deviation, results in the increase in entrepreneurial intention, by a 0.121 standard deviation. An improvement of labor regulation by 1 standard deviation results in a decrease in latent entrepreneurship by a 0.122 standard deviation. As credit, labor and business regulations are a sub-component of the regulation area of the EFW index, there is a concern of multicollinearity in the regression. For that purpose, I have run the model, including each sub-component of regulation, separately (Model 2, 3 and 4 respectively). But the results remain consistent, the magnitude of the coefficients of the labor market changes slightly.

Table 3.4 shows that, expectedly, employment in the agricultural sector has a significant positive effect on latent entrepreneurship. This implies that countries that have a bigger agricultural sector will possess higher levels of latent entrepreneurs. This result should be interpreted with caution, however, because self-employment in the agricultural sector is not considered to be an entrepreneurial activity.

Furthermore, I have found that freedom to trade internationally negatively affects entrepreneurial intention. A possible explanation may be that a lower tariff rate and exchange rate attracts higher Foreign Direct Investment, thus creating more jobs and a lower latent entrepreneurship rate. However, I have failed to find any significant effect regarding the size of government on entrepreneurial intention.

To check robustness, I have run a fixed effects panel regression with interpolated data for entrepreneurial intention. This also addresses the problem of missing observations within an unbalanced panel structure. I have used the methods of interpolation and extrapolation for replacing the missing observations of entrepreneurial intention. Table 3.5 reports the result for the fixed effect panel regression, controlling for year effects. I have also used linear interpolation and extrapolation on the basis of preceding years. The results are consistent for all such methods. The results for the re-estimation, using interpolation and extrapolation, show some difference from the original regression results in terms of significance of variables and also magnitude of coefficients in some cases. However, I have only used interpolation and extrapolation for replacing missing values in the cases where $70 \%$ of data were already present. 
Model 1 of Table 3.5 shows that regulation has a significant positive effect on latent entrepreneurship. Model 2 shows that similar effects of labor regulation as obtained in previous regressions. However, the credit market does not have significant impact on latent entrepreneurship, unlike those obtained from the baseline regression. For a further robustness check, I excluded the countries with very few observations from the sample. Bangladesh, for example, had observations for only 2011. Table 3.6 presents the results after omitting the countries with very few observations. These results are consistent with baseline regressions, with a minimal change in magnitude. This suggests that credit and labor market regulations, along with the freedom to trade internationally and legal rights, are robust to excluding particular observations and is not sensitive towards exclusion of particular observations.

\subsection{Conclusion}

This paper contributes to the empirical literature regarding the determinants of latent entrepreneurship. It investigates the relationship between institutional qualities and latent entrepreneurship. The paper uses data for entrepreneurial intentions from the GEM Report, for 79 countries (from 2001 to 2016). It highlights the role of the five components of the Economic Freedom Index (size of government, legal structure and property rights, access to sound money, barriers for international trade and credit, labor and business regulations) on latent entrepreneurship. However, it mainly focuses on the role of the regulatory framework on entrepreneurial intention. The empirical data confirms the findings of Nyström (2008) and Van Stel et al. (2007); credit regulation has a significant positive effect on entrepreneurial intention. The findings of this paper, however, state that a stricter labor regulation may encourage higher latent entrepreneurship. This signals towards necessity based entrepreneurship in transition economies. For most of the people in a developing country, entrepreneurship is a survival strategy rather than a choice, as strict labor regulations, including rigid hiring and firing regulations, longer duration of fixed term employment con- 
tracts reduce the job availability. Furthermore, I do not find any significant impact regarding business regulations. This finding is consistent with the above argument of necessity based entrepreneurship, because, in the developing countries, the majority of latent entrepreneurship accounts for entrepreneurship in the informal sector Van Stel et al. (2007). This brings up another shortcoming of the data; it does not differentiate between formal and informal entrepreneurship.

As expected, this result shows that individuals might be more willing to take up entrepreneurship as a new career option in a less stringent regulatory environment. This is especially true with credit market regulations, facilitating an easier availability of capital for a start-up. However, strict labor market regulations actually encourage latent entrepreneurship. These results are significant in terms of their public policy implications. Such transition economies, with sluggish employment contracts and rigid hiring and firing regulations, will exhibit a higher rate of entrepreneurship by improving legal structures, property rights and by providing better financial support to the aspiring entrepreneurs via the easing of credit regulations.

However, this paper has some limitations. As GEM data does not track a particular individual through several time periods, a question remains regarding the conversion rate of the latent entrepreneurs into active entrepreneurs. It would be very interesting to know how different elements of economic freedom facilitates the conversion of latent entrepreneurs into active business owners. Moreover, according to the literature (Angulo-Guerrero et al., 2017; Van Stel et al., 2007) the relationship between economic freedom and opportunity and necessity based entrepreneurial activities are quite different. Arguing in the same line, it would be very helpful to differentiate the effect of economic freedom on opportunity and necessity based entrepreneurial intentions. But the GEM data is limited in terms of reporting necessity and opportunity based entrepreneurial intention measures. Lastly, given the GEM data in heavily unbalanced the results should be interpreted with caution. 
Table 3.1: Summary Statistics

\begin{tabular}{lrrrrr}
\hline \multicolumn{1}{c}{ Variable } & Observations & Mean & St. Dev. & Min & \multicolumn{1}{c}{ Max } \\
\hline Entrepreneurial intentions & 449 & 15.18 & 12.35 & 0.750 & 62.56 \\
Size of government & 449 & 5.829 & 1.235 & 3.090 & 8.790 \\
Legal system propertyrights & 449 & 6.732 & 1.399 & 3.370 & 9.140 \\
Soundmoney & 449 & 8.922 & 0.994 & 4.130 & 9.890 \\
Freedom to trade internationally & 449 & 7.796 & 0.757 & 3.440 & 9.220 \\
Regulation & 449 & 7.185 & 0.789 & 4.340 & 8.940 \\
Creditmarket regulations & 449 & 8.827 & 1.060 & 4.670 & 10 \\
Labormarket regulations & 449 & 6.295 & 1.327 & 3.340 & 9.280 \\
Business regulations & 449 & 6.435 & 0.792 & 3.360 & 8.890 \\
FDI & 449 & 4.861 & 7.995 & -16.07 & 87.44 \\
GDP per capita at constant 2005 dollars & 449 & 29,322 & 21,815 & 392.2 & 105,853 \\
Percentage of female & 449 & 50.84 & 0.974 & 48.14 & 54.31 \\
Percentage of population 15 to 64 age & 449 & 66.34 & 2.888 & 47.91 & 74.35 \\
Primary school enrollment & 449 & 104.7 & 7.553 & 91.65 & 146.8 \\
Secondary school enrollment & 449 & 101.9 & 17.21 & 19.63 & 164.8 \\
Unemployment & 449 & 8.157 & 4.857 & 0.580 & 27.47 \\
Percentage of agricultural employment & 449 & 9.931 & 11.22 & 0.610 & 73.79 \\
Market capitalization & 449 & 70.55 & 12.22 & 39.69 & 88.75 \\
\hline
\end{tabular}

Note: Time Period: 2001-2016 
Table 3.2: Effect of Regulation on Entrepreneurial Intention

\begin{tabular}{lrr}
\hline \multicolumn{1}{c}{ Variable } & Model 1 & Model2 \\
\hline Credit market regulations & $\begin{array}{r}1.662^{* * *} \\
(0.421)\end{array}$ & \\
Labor market regulations & $-1.697^{* *}$ & \\
& $(0.667)$ & \\
Business regulations & -0.469 & \\
& $(0.700)$ & \\
Regulation & & $3.607^{* * *}$ \\
& & $(0.897)$ \\
Constant & -7.073 & -3.602 \\
& $(6.376)$ & $(6.826)$ \\
\hline Country fixed effects & Yes & Yes \\
Year fixed effects & Yes & Yes \\
Observations & 449 & 449 \\
R-squared & 0.031 & 0.045 \\
\hline
\end{tabular}

Note: Dependent variable is Entrepreneurial Intention, Time Period: 2001-2016, Robust Standard errors in parentheses. ${ }^{* * *} \mathrm{p}<0.01,{ }^{* *} \mathrm{p}<0.05,{ }^{*} \mathrm{p}<0.1$ 
Sriparna Ghosh

Table 3.3: Effect of Regulation on Entrepreneurial Intention with controls

\begin{tabular}{|c|c|c|c|}
\hline Variable & Model1 & Model2 & Model3 \\
\hline \multirow[t]{2}{*}{ Size of government } & 0.194 & 0.268 & 0.435 \\
\hline & $(0.766)$ & $(0.781)$ & $(0.744)$ \\
\hline \multirow[t]{2}{*}{ Legal system property rights } & $3.628 * *$ & $4.130 * * *$ & $4.300^{* * *}$ \\
\hline & $(1.287)$ & $(1.296)$ & $(1.321)$ \\
\hline \multirow[t]{2}{*}{ Sound money } & 0.244 & 0.165 & 0.180 \\
\hline & $(0.792)$ & $(1.129)$ & $(1.100)$ \\
\hline \multirow[t]{2}{*}{ Freedom to trade internationally } & $-4.616^{* * *}$ & $-3.556^{* * *}$ & $-3.318 * * *$ \\
\hline & $(1.649)$ & $(1.707)$ & $(1.658)$ \\
\hline \multirow[t]{2}{*}{ Regulation } & $3.169^{*}$ & $3.492^{*}$ & \\
\hline & $(1.776)$ & $(2.697)$ & \\
\hline \multirow[t]{2}{*}{ Credit market regulations } & & & $1.558^{* *}$ \\
\hline & & & $(0.732)$ \\
\hline \multirow[t]{2}{*}{ labor market regulations } & & & $-2.041^{* *}$ \\
\hline & & & $(0.940)$ \\
\hline \multirow[t]{2}{*}{ Business market regulations } & & & 1.813 \\
\hline & & & $(1.609)$ \\
\hline \multirow[t]{2}{*}{ Primary school enrollment } & & -0.0727 & -0.022 \\
\hline & & $(0.164)$ & $(0.147)$ \\
\hline \multirow[t]{2}{*}{ Secondary school enrollment } & & -0.009 & -0.024 \\
\hline & & $(0.054)$ & $(0.052)$ \\
\hline \multirow[t]{2}{*}{ Percentage of population 15 to 64 age } & & 0.249 & -0.237 \\
\hline & & $(0.543)$ & $(0.614)$ \\
\hline \multirow[t]{2}{*}{ GDP per capita at constant 2005} & & -0.003 & -0.001 \\
\hline & & $(0.001)$ & $(0.001)$ \\
\hline \multirow[t]{2}{*}{ Market capitalization } & & 0.027 & 0.024 \\
\hline & & $(0.022)$ & $(0.025)$ \\
\hline \multirow[t]{2}{*}{ FDI } & & -0.031 & -0.032 \\
\hline & & $(0.031)$ & $(0.032)$ \\
\hline \multirow[t]{2}{*}{ Percentage of unemployed } & & -0.118 & -0.101 \\
\hline & & $(0.001)$ & $(0.001)$ \\
\hline Country fixed effects & Yes & Yes & Yes \\
\hline Year fixed effects & Yes & Yes & Yes \\
\hline Observations & 449 & 449 & 449 \\
\hline Within R-squared & 0.141 & 0.229 & 0.234 \\
\hline Between R-squared & 0.262 & 0.244 & 0.229 \\
\hline Overall R-squared & 0.214 & 0.170 & 0.140 \\
\hline F statistic & 3.350 & 5.000 & 5.580 \\
\hline Prob $>$ F & 0.000 & 0.000 & 0.000 \\
\hline Rho & 0.932 & 0.879 & 0.881 \\
\hline
\end{tabular}

Note: Dependent variable is Entrepreneurial Intention, Time Period: 2001-2016, Robust Standard errors in parentheses. $* * * \mathrm{p}<0.01, * * \mathrm{p}<0.05, * \mathrm{p}<0.1$ 
Table 3.4: Effect of Regulation on Entrepreneurial Intention with Country and year Fixed effects

\begin{tabular}{|c|c|c|c|c|c|}
\hline Variables & Model 1 & Model 2 & Model 3 & Model 4 & Model 5 \\
\hline \multirow[t]{2}{*}{ Size of government } & 0.610 & 0.252 & 0.985 & 0.946 & 0.339 \\
\hline & $(0.778)$ & $(0.779)$ & $(0.788)$ & $(0.821)$ & $(0.747)$ \\
\hline \multirow[t]{2}{*}{ Legal system property rights } & $1.599^{*}$ & $1.689^{* *}$ & $1.617^{*}$ & $1.536^{*}$ & $1.650^{*}$ \\
\hline & $(0.819)$ & $(0.830)$ & $(0.836)$ & $(0.806)$ & $(0.829)$ \\
\hline \multirow[t]{2}{*}{ Sound money } & 0.264 & 0.216 & 0.437 & 0.405 & 0.305 \\
\hline & $(0.989)$ & $(1.036)$ & $(0.963)$ & $(1.035)$ & $(0.981)$ \\
\hline \multirow[t]{2}{*}{ Freedom to trade internationally } & $-3.432^{* * *}$ & $-3.339 * * *$ & $-3.544^{* * *}$ & $-3.599 * * *$ & $-3.472^{* * *}$ \\
\hline & $(0.871)$ & $(0.842)$ & $(0.864)$ & $(0.830)$ & $(0.831)$ \\
\hline \multirow[t]{2}{*}{ Regulation } & 2.064 & & & & \\
\hline & $(0.187)$ & & & & \\
\hline \multirow[t]{2}{*}{ Credit market regulations } & & $1.553^{* *}$ & & & $1.569^{* *}$ \\
\hline & & $(0.766)$ & & & $(0.725)$ \\
\hline \multirow[t]{2}{*}{ labor market regulations } & & & $-1.840^{*}$ & & $-2.029^{* *}$ \\
\hline & & & $(0.967)$ & & $(0.952)$ \\
\hline \multirow[t]{2}{*}{ Business regulations } & & & & 1.944 & 1.714 \\
\hline & & & & $(1.857)$ & $(1.565)$ \\
\hline \multirow[t]{2}{*}{ Percentage of employment in agricultural sector } & $0.0179 *$ & $0.0186^{* *}$ & $0.0179^{*}$ & $0.0170^{*}$ & $0.0173^{*}$ \\
\hline & $(0.00955)$ & $(0.00898)$ & $(0.00910)$ & $(0.00970)$ & $(0.00919)$ \\
\hline \multirow[t]{2}{*}{ Primary school enrollment } & 0.009 & 0.009 & 0.005 & 0.003 & 0.0001 \\
\hline & $(0.154)$ & $(0.156)$ & $(0.161)$ & $(0.149)$ & $(0.155)$ \\
\hline \multirow[t]{2}{*}{ Secondary school enrollment } & 0.017 & 0.017 & 0.018 & 0.016 & 0.016 \\
\hline & $(0.027)$ & $(0.029)$ & $(0.028)$ & $(0.027)$ & $(0.027)$ \\
\hline \multirow[t]{2}{*}{ Percentage of population 15 to 64 age } & 0.229 & 0.200 & 0.222 & 0.0372 & -0.242 \\
\hline & $(0.526)$ & $(0.535)$ & $(0.538)$ & $(0.518)$ & $(0.587)$ \\
\hline \multirow[t]{2}{*}{ Percentage of female } & 2.923 & 2.852 & 3.229 & 3.053 & 2.912 \\
\hline & $(2.425)$ & $(2.481)$ & $(2.412)$ & $(2.231)$ & $(2.570)$ \\
\hline \multirow[t]{2}{*}{ s GDP per capita at constant 2005} & -0.0004 & -0.0004 & -0.0004 & -0.0003 & -0.0001 \\
\hline & $(0.0008)$ & $(0.0003)$ & $(0.0003)$ & $(0.0003)$ & $(0.0001)$ \\
\hline \multirow[t]{2}{*}{ Constant } & 10.22 & 13.95 & 20.86 & 19.93 & 35.63 \\
\hline & $(34.25)$ & $(33.50)$ & $(34.27)$ & $(36.85)$ & $(36.75)$ \\
\hline Observations & 449 & 449 & 449 & 449 & 449 \\
\hline Within R-squared & 0.121 & 0.122 & 0.119 & 0.121 & 0.125 \\
\hline Between R-squared & 0.387 & 0.436 & 0.366 & 0.352 & 0.414 \\
\hline Overall R-squared & 0.227 & 0.270 & 0.184 & 0.205 & 0.277 \\
\hline F statistic & 3.20 & 3.12 & 3.380 & 3.430 & 3.10 \\
\hline Prob $>$ F & 0.001 & 0.001 & 0.001 & 0.000 & 0.001 \\
\hline Rho & 0.922 & 0.928 & 0.921 & 0.922 & 0.934 \\
\hline
\end{tabular}

Note: Dependent variable is Entrepreneurial Intention, Time Period: 2001-2016, Robust Standard errors in parentheses. ${ }^{* * *} \mathrm{p}<0.01,{ }^{* *} \mathrm{p}<0.05,{ }^{*} \mathrm{p}<0.1$ 
Table 3.5: Effect of Regulation on Entrepreneurial Intention with interpolated data

\begin{tabular}{|c|c|c|}
\hline Variables & Model 1 & Model 2 \\
\hline Size of government & $\begin{array}{c}0.0483 \\
(0.508)\end{array}$ & $\begin{array}{r}0.198 \\
(0.584)\end{array}$ \\
\hline Legal system property rights & $\begin{array}{c}2.164^{*} \\
(1.424)\end{array}$ & $\begin{array}{c}2.127^{*} \\
(1.565)\end{array}$ \\
\hline Sound money & $\begin{array}{r}0.358 \\
(0.526)\end{array}$ & $\begin{array}{r}0.351 \\
(0.592)\end{array}$ \\
\hline Freedom to trade internationally & $\begin{array}{c}0.406^{*} \\
(0.617)\end{array}$ & $\begin{array}{r}1.200^{*} \\
(0.676)\end{array}$ \\
\hline Business regulation & & $\begin{array}{r}0.454 \\
(0.433)\end{array}$ \\
\hline Labor market regulations & & $\begin{array}{r}-1.678^{*} \\
(0.941)\end{array}$ \\
\hline Credit market regulations & & $\begin{array}{c}0.779^{*} \\
(0.472)\end{array}$ \\
\hline Regulation & $\begin{array}{r}2.305^{* * *} \\
(0.870)\end{array}$ & \\
\hline Constant & $\begin{array}{r}-16.20 \\
(11.05)\end{array}$ & $\begin{array}{r}-27.89 * * \\
(13.37)\end{array}$ \\
\hline Observations & 589 & 589 \\
\hline Within R-squared & 0.048 & 0.059 \\
\hline Between R-squared & 0.348 & 0.459 \\
\hline Overall R-squared & 0.146 & 0.158 \\
\hline F statistic & 4.38 & 4.30 \\
\hline Prob > F & 0.000 & 0.000 \\
\hline rho & 0.981 & 0.984 \\
\hline
\end{tabular}

Note: Dependent variable is Entrepreneurial Intention, Time Period: 2001-2016, Robust Standard errors in parentheses. ${ }^{* * *} \mathrm{p}<0.01,{ }^{* *} \mathrm{p}<0.05,{ }^{*} \mathrm{p}<0.1$ 
Table 3.6: Effect of Regulation on Entrepreneurial Intention excluding countries with less observations

\begin{tabular}{|c|c|c|}
\hline Variables & Model 1 & Model 2 \\
\hline \multirow[t]{2}{*}{ Size of government } & 0.422 & 0.144 \\
\hline & $(0.821)$ & $(0.762)$ \\
\hline \multirow[t]{2}{*}{ Legal system property rights } & $4.510^{* * *}$ & $4.608^{* * *}$ \\
\hline & $(1.576)$ & $(1.535)$ \\
\hline \multirow[t]{2}{*}{ Sound money } & 0.449 & 0.388 \\
\hline & $(1.189)$ & $(0.974)$ \\
\hline \multirow[t]{2}{*}{ Freedom to trade internationally } & $-4.989 * * *$ & $-4.997 * * *$ \\
\hline & $(1.747)$ & $(1.695)$ \\
\hline \multirow[t]{2}{*}{ Credit market regulations } & & $1.333^{* *}$ \\
\hline & & $(0.620)$ \\
\hline \multirow[t]{2}{*}{ Labor market regulations } & & $-2.126^{* *}$ \\
\hline & & $(0.912)$ \\
\hline \multirow[t]{2}{*}{ Business regulations } & & 1.063 \\
\hline & & $(1.105)$ \\
\hline \multirow[t]{2}{*}{ Percentage of employment in agricultural sector } & -0.706 & -0.801 \\
\hline & $(0.800)$ & $(0.752)$ \\
\hline \multirow[t]{2}{*}{ Primary school enrollment } & 0.00977 & 0.0475 \\
\hline & $(0.152)$ & $(0.141)$ \\
\hline \multirow{2}{*}{ Secondary school enrollment } & -0.00978 & -0.0208 \\
\hline & $(0.0530)$ & $(0.0510)$ \\
\hline \multirow[t]{2}{*}{ Percentage of population 15to64 age } & -0.0544 & -0.511 \\
\hline & $(0.551)$ & $(0.605)$ \\
\hline \multirow[t]{2}{*}{ GDP per capita at constant 2005} & -0.000214 & $-3.89 \mathrm{e}-05$ \\
\hline & $(0.000298)$ & $(0.000258)$ \\
\hline \multirow[t]{2}{*}{ Regulation } & 1.242 & \\
\hline & $(1.291)$ & \\
\hline \multirow[t]{2}{*}{ Constant } & 24.20 & 52.54 \\
\hline & $(42.16)$ & $(43.54)$ \\
\hline Observations & 500 & 500 \\
\hline Within R-squared & 0.259 & 0.301 \\
\hline Between R-squared & 0.348 & 0.459 \\
\hline Overall R-squared & 0.315 & 0.308 \\
\hline F statistic & 4.38 & 4.30 \\
\hline Prob $>F$ & 0.000 & 0.000 \\
\hline Rho & 0.904 & 0.913 \\
\hline
\end{tabular}

Note: Dependent variable is Entrepreneurial Intention, Time Period: 2001-2016, Robust Standard errors in parentheses. ${ }^{* * *} \mathrm{p}<0.01,{ }^{* *} \mathrm{p}<0.05,{ }^{*} \mathrm{p}<0.1$ 


\section{Chapter 4}

\section{Growth-Enhancing Economic Freedom}

\subsection{Introduction}

A large and robust literature has established a strong correlation between economic freedom and good economic outcomes. Economic freedom is a broad concept encapsulating numerous policy decisions aimed at protecting individuals from physical harms caused by others and defending property rights from encroachment. ${ }^{1}$ Measurements of economic freedom include fiscal policy dimensions (such as size of government spending and taxation), the quality of publicly provided protection services (such as an independent judiciary free from corruption), and the regulation of markets (such as occupational licensing in labor markets).

The diverse components of economic freedom can be expected to interact with one another. Removing restrictions in labor markets, for example, will have a more substantial impact on society's economic well-being if the tax burden placed on workers' incomes is less. Improving economic freedom in one dimension does not necessarily have an effect that is independent of the degree of liberty available in other areas.

Therefore, our objective is to use economic freedom measurements to identify

\footnotetext{
${ }^{1}$ For an excellent, clear definition of economic freedom see (Gwartney et al., 1996), www.freetheworld.com.
} 
which dimensions are most important for improving economic quality of life. In particular, we want to determine which aspect of economic freedom has the greatest marginal impact on citizens' well-being. For our normative evaluation of "good impact" we choose to look at a U.S. state's real GDP per capita. This is an appropriate and common first step in evaluating economic policies at the state level. Our methods, though, could be applied to alternative macroeconomic variables.

Hence, one may think of our research objective as being able to respond to the following scenario. Suppose one has the opportunity to make a statement in, for example, a regional news outlet suggesting one and only one policy reform that would help the residents of that state the most. How does one choose for that particular state which policy to change first? Can economic freedom indices be used as a guide?

To provide a framework to answer this question, we use the Economic Freedom of North America index (hereafter EFNA), which measures economic freedom at the state level in three important dimensions: size of government, burden of taxation, and labor market freedom. Rather than equally weight each component and sum the three scores, as is done in the EFNA, we construct an econometric "best fit" between the EFNA components and real GDP per capita, allowing for nonlinearities and interaction effects. The coefficients derived from this exercise are used as weights in the construction of a "growth-enhancing" economic freedom score (hereafter GE-EFNA). Consequently, the best-fitted relationship allows for interdependent and nonlinear marginal benefits to improved economic freedom in each area. We use this to identify, for each state in the U.S. for the most recent EFNA data, which area of economic freedom can be expected to lead to the greatest improvement in economic well-being.Even though the construction of growth-enhancing economic freedom index using state level economic freedom data is quite unique, some studies have tried to construct growth maximizing indexes based on EFW. Heckelman and Stroup (2002) have used similar methodology to construct an alternative index, using weights representing relevance to growth. On the other hand, Beaulier et al. (2016) have used an ordinal ranking, based on ordering the components of EFW according to their 
respective importance, to construct an alternative index for ranking the institutions of countries.

Along with providing the guide on how to use economic freedom scores for policy, we put our measurement to the test. We argue that participants in financial markets are incentivized to fully incorporate available information. In state bond markets, then, analysts should have responded to a state's ability to repay its debts. This intuition has been explored by Calcagno and Benefield (2013) and Belasen et al. (2015). They show that the EFNA index is highly correlated with state bond ratings. We follow their lead in using economic freedom as a correlate with the evaluation of a state's fiscal health. We hypothesize though, that our GE-EFNA score provides a better forecast of a state's bond rating.

We present empirical evidence supporting our claim. Both the EFNA and GEEFNA indices are highly correlated with state bond ratings. Controlling for the state's EFNA score, the GE-EFNA index has an additional and statistically significant explanatory value. In fact, using the GE-EFNA score provides a better fitting econometric model than just the unweighted EFNA index. Thus, our growth-enhancing economic freedom measurement is a valuable tool in guiding policy.

Section 2 of the paper briefly describes the literature on state-level economic freedom and its relationship with good macroeconomic outcomes. Section 3 describes the data used in the analysis and Section 4 presents the estimation. Our measurement's application to state bond ratings is done in Section 5. Section 6 concludes.

\subsection{Economic Freedom and Research Findings}

Economic institutions can be evaluated based on the amount of economic freedom they provide. The Economic Freedom of World index (hereafter EFW) (Gwartney, 2009) captures the extent to which individuals in different countries are free to engage in voluntary transactions. This includes the degree of government intervention into people's lives, property rights protection, maintaining free labor mobility/choice, and 
sound money. The EFW index has been constructed based on policy in five major areas namely, (a) size of government, (b) legal system and security of property rights, (c) sound money, (d) freedom to trade internationally, and (e) regulation. Starting with 100 countries in 1980, the EFW now covers 159 countries. An extensive literature focuses on the effect of economic freedom on growth and development (Powell, 2002; Gwartney et al., 2004; Ionescu, 2014; Justesen, 2008; Gwartney and Lawson, 2008; Rode and Coll, 2012). ${ }^{2}$

As the EFW index measures differences in economic freedom across countries, the Economic Freedom of North America index is a measure of economic freedom for all fifty states of U.S., ten Canadian provinces, and thirty-two Mexican states (Ionescu, 2014). The EFNA index takes values on a scale between zero and ten, with greater numbers indicating higher levels of economic freedom. The EFNA index is based on data on three main areas namely, size of government (Area 1), takings and discriminatory taxations (Area 2), and labor market freedom (Area 3). The overall EFNA value is an unweighted average of the scores from the three areas.

A large literature has focused on the correlation between economic freedom and state-level macroeconomic variables. For example, Campbell et al. (2010) show that a higher EFNA score is associated with higher income growth. Compton et al. (2014) revisit the relationship and conclude that economic freedom has positive relationship with mean household income. Wiseman (2017) finds that an increase in the EFNA score is associated with larger income growth rates for income earners belonging to the bottom $90 \%$ relative to the top $10 \%$. Therefore, there is a strong empirical relationship between state-level economic freedom and incomes.

Connecting state-level GDP to its microeconomic foundations, Kreft and Sobel (2005) argue that entrepreneurial activity acts as a "missing link" between economic growth and economic freedom. Numerous empirical investigations have established a link between economic freedom and entrepreneurship (Sobel, 2008; Hall and Sobel,

\footnotetext{
${ }^{2}$ We do not attempt to fully document all of the interesting and important research on crosscountry differences in economic freedom and other macroeconomic variables. The research is simply too vast to adequately cite here.
} 
2008; Wiseman and Young, 2013). Specific investigations have connected the EFNA index to firm births and deaths (Campbell et al., 2007; Goetz and Rupasingha, 2009; Cumming and Li, 2013; Campbell et al., 2012)).

Even though a majority of the studies focus on the relationship between economic freedom and income, economic growth, and entrepreneurship, important relationships with other variables have been considered. Numerous studies have, for example, established that states with greater economic freedom exhibit higher in-migration rates and higher population growth (Ashby, 2007; Watkins and Yandle, 2010; Cebula and Clark, 2011; Mulholland and Hernández-Julián, 2013; Cebula, 2014). Relatedly, Heller and Stephenson (2014) explore the relationship between economic freedom and unemployment rates, while its correlation with female labor force participation has been established (Cebula and Alexander, 2015). Additionally, the relationship between economic freedom and income inequality has been evaluated (Ashby and Sobel, 2008; Bennett and Vedder, 2013; Apergis et al., 2014). The EFNA index is positively related to other economic outcomes like lower software piracy (Bezmen and Depken, 2006), quality of prosecution services provided (Detotto and McCannon, 2017), personal physical and intelligence characteristics (Belasen et al., 2015), diminished municipal bond fund mispricing (Jones and Stroup, 2013), housing price appreciation (Campbell et al., 2007), FDI flows into a state (Pearson et al., 2012), and higher stock market returns (Stocker, 2005).

Therefore, this expansive literature has established a strong, positive relationship between economic freedom and "good" economic outcomes. It is reasonable, then, to ask how these measurements can be used to guide policy improvements. Identifying the functional specification that best maps the areas making up the EFNA index to state-level GDP is appropriate and valuable. 


\subsection{Data}

As discussed, a popular measure of economic freedom is the EFNA index. It is constructed based on ten components which fall under three broad areas. Each of the three areas is assigned a score based on several underlying components. Area 1 is government spending, which is based on (a) general consumption expenditure by the state government, (b) transfers and subsidies, and (c) insurance and retirement payments. The Area 2 score taxes is based on (a) income and payroll tax revenue, (b) the top marginal income tax rate, (c) property taxes, and (d) sales taxes. Area 2 captures losses due to taxation which constrains investment and consumption. The Area 3 score represents labor market freedom: (a) minimum wage legislation, (b) government employment, and (c) union density. The components of Area 3 measure the loss in economic freedom due to restrictions imposed on the employers and employees.

Therefore, the scores for all fifty states for each area of economic freedom between 2004 and 2013 (the most recent data available) is used. ${ }^{3}$ Additionally, we use each state's real GDP per capita as the measurement of a strong state economy. Data over this time period is collected from Bureau of Economic Analysis. As a consequence, a panel data set is created.

In the Economic Freedom of North America Report, the data for each area's components are quantified into scores ranging from zero to ten. Table 4.1 provides the descriptive statistics.

Nevada in 2001 shows the maximum score for government spending, while New Hampshire in 2000 and 2001 shows highest economic freedom in terms of taxes. Virginia in 2007 has the highest labor market freedom. Economic freedom varies between the states. Across the country, though, it has been improving recently. Figure 4.1 depicts the average EFNA score averaged for the fifty states for each year.

Economic quality-of-life across the fifty states experiences a substantial amount

\footnotetext{
${ }^{3}$ The data is available at www.freetheworld.com. The EFNA index is measured in both the subnational and the all-government indices. The latter measures the impact from all levels of government (federal, state, and municipal). The former does not include the national government. We use the subnational index.
} 
of variation as well. GDP's maximum value is over 2.6 times as large as the lowest state in the country.

\subsection{Results}

The objective of the analysis is to use the economic freedom data as a guide to economic policy reform. To achieve this goal, the three components that comprise the EFNA index are used as explanatory variables, regressed against real GDP per capita.

Our econometric strategy is to identify the "best fitted" relationship between the measurements. Thus, we use a state's real GDP per capita in a year as the dependent variable. Rather than consider the EFNA score aggregated from its three components, we leave them disaggregated. Furthermore, we consider a squared value of each component. Also, we include the interaction terms between them as well. Thus, our econometric specification is to allow the regression analysis to provide the functional relationship between economic freedom and real GDP per capita that best explains the data. The following econometric model is estimated.

$$
\begin{gathered}
G D P_{t d}=\beta_{0}+\beta_{1} A 1_{t d}+\beta_{2} A 1_{t d}^{2}+\beta_{3} A 2_{t d}+\beta_{4} A 2_{t d}^{2}+\beta_{5} A 3_{t d}+ \\
\beta_{6} A 3_{t d}^{2}+\beta_{7} A 1_{t d} \times A 2_{t d}+\beta_{8} A 1_{t d} \times A 3_{t d}+ \\
\beta_{9} A 2_{t d} \times A 3_{t d}+\beta_{10} A 1_{t d} \times A 2_{t d} \times A 3_{t d}+\epsilon_{t d}
\end{gathered}
$$

where $t$ denotes state and d denotes year. Our econometric strategy is similar to a White Test for heteroscedasticity in that all nonlinearites and interaction terms are included to best fit the econometric relationship. The benefit of this model is that it allows for nonlinear and interdependent marginal valuations as well. If the standard calculation of economic freedom is optimal for forecasting GDP, then

$$
\beta_{1}=\beta_{3}=\beta_{5}>0, \text { while } \beta_{2}=\beta_{4}=\beta_{6}=\beta_{7}=\beta_{8}=\beta_{9}=\beta_{10}=0 .
$$

Table 4.2 provides the estimation results.

An F-test of the joint hypothesis that all of the coefficients other than $\beta_{1}, \beta_{3}$ and 
$\beta_{5}$ are zero can be rejected $(\mathrm{F}$-stat $=26.3$ in I and 9.0 in II, both with $\mathrm{p}<0.001)$. Therefore, the nonlinear, interdependent model is an improvement over the standard EFNA calculation as it provides a better fit to real GDP per capita.

The estimation indicates that there are important nonlinear and interdependent effects between the components of economic freedom. The two columns differ in whether state and year fixed effects are included. In II, while the coefficients are jointly significant predictors of GDP, their individual significance is diminished when state and year fixed effects are included. Since our focus is on the goodness of fit of the model, the significance of any one variable is not of primary importance.

The estimation presented in Table 4.2 provides two distinct values. First, the estimated coefficients can be used to calculate the marginal value of improving each of the three areas of economic freedom. Table 4.3 presents the marginal values.

Specifically, the most recent values for Area 1, Area 2, and Area 3 are used. We use the coefficients estimated to create a marginal value to improving each area. This allows us to identify the area that leads to the greatest increase in economic wellbeing. Table 4.3 presents, for each state in 2013, the dimension that has the highest marginal value, along with the estimated marginal effect.

There is substantial dispersion in the area of economic freedom that states need to improve upon. Nine states would receive the greatest benefit from reducing government spending (Area 1), twelve states obtain the greatest benefit from improving tax policy (Area 2), and twenty-nine states should focus on labor market freedom (Area 3).

It is important to point out that the interaction terms between the three areas of economic freedom have positive coefficients. This implies that there are important complementarities between the components. As hypothesize in the introduction, an improvement in labor market freedom has a larger impact on a state's economy when taxation is less punitive. In Table 4.2 a one unit increase in the index for tax policy increases the marginal value of labor market freedom improvements by 0.38 (approximately three-fifths of a standard deviation). Thus, those states in Table 4.3 who are 
identified as having labor markets as the area of need, to continue with the example, will be those with more conducive fiscal policies.

Relatedly, the results suggest that there are important nonlinear effects. Using the mean values, each area has a positive relationship with GDP and has increasing returns. This suggests, holding fixed the amount of economic freedom in the other two dimensions for example, a reduction in the government's size and scope experiences escalating returns. States that have made improvements by reducing, for a specific example, subsidies tend to find additional value from other improvements in reducing government size.

While Table 4.3 focuses on the marginal value of improved economic freedom, a second value exists to the estimation presented in Table 4.2. The coefficients can be used to create a new index of economic freedom. We refer to it as the GrowthEnhancing Economic Freedom of North America index (hereafter GE-EFNA). Simply, we use the coefficients presented in equation (1) to calculate the GE-EFNA score. As stated, the EFNA index creates an unweighted average of the three scores,

$$
E F N A_{t d}=(1 / 3) A 1_{t d}+(1 / 3) A 2_{t d}+(1 / 3) A 3_{t d}
$$

We propose to use the estimated coefficients to calculate a weighted, nonlinear index,

$$
\begin{aligned}
G E \_E F N A_{-} t d & =\hat{\beta}_{1} A 1_{t d}+\hat{\beta}_{2} A 1_{t d}^{2}+ \\
& \hat{\beta}_{3} A 2_{t d}+\hat{\beta}_{4} A 2_{t d}^{2}+ \\
& \hat{\beta}_{5} A 3_{t d}+\hat{\beta}_{6} A 3_{t d}^{2}+ \\
& \hat{\beta}_{7} A 1_{t d} \times A 2_{t d}+\hat{\beta}_{8} A 1_{t d} \times A 3 t d+ \\
& \hat{\beta}_{9} A 2_{t d} \times A 3_{t d}+\hat{\beta}_{10} A 1_{t d} \times A 2 t d \times A 3_{t d}
\end{aligned}
$$

Table 4.1 provides the GE-EFNA scores and state rankings, comparing them to the rankings generated by the EFNA index. As one would expect, the two are highly correlated $(\mathrm{r}=0.87)$. Table 4.7 presents the goodness of fit measurements across numerous new specifications to test the robustness of the results presented 
in Table 4.5. Labor market data are obtained from the Bureau of Labor Statistics. Specifically, population, labor force, and unemployment are used to calculate the labor force participation rate and unemployment rate for each state within each year. Additionally, while the main results in Table 4.5 use a fixed effect model to control for state-specific economic and non-economic factors which are time-invariant and year fixed effects to control for country-wide macroeconomic events, the dependent variable is ordinal. Therefore, one may be concerned that this is an inappropriate model to use. Consequently, the goodness of fit measurements across the three specifications using the alternative methods can be compared.

Table 4.6 presents the GE-EFNA score for each state in 2013. It also provides the state's ranking in both the GE-EFNA and EFNA calculation for the year. To normalize the GE-EFNA score, an affine transformation is used. The slope and intercept term is constructed so that the maximum (minimal) value of the GE-EFNA score in the panel data set equals the maximal (minimal) value of the EFNA value in the pane. ${ }^{4}$

In our analysis, as discussed, we choose to use real GDP per capita as our normative measurement of good economic outcomes. This is done to create a weighted index that captures each component's differing importance in achieving good economic outcomes. One can easily reproduce the analysis, instead of fitting economic freedom to state income, by choosing an alternative economic variable (e.g. unemployment, median income, and poverty rate). However, Heckelman and Stroup (2002) have adopted similar methodology to create an index which is based on contribution of each freedom measure towards economic growth. They further use the coefficients obtained from regressing the fourteen components of EFW on economic growth rate to construct weights for the overall summary rating for each country.

\footnotetext{
${ }^{4}$ Thus, the reported score is equal to $7.554455+1.026323 *$ GE-EFNA.
} 


\subsection{Using the GE-EFNA}

We argue that our index can be used to guide economic policy. For our argument to be persuasive, evidence that it is an improvement over the standard EFNA index is needed. We hypothesize that if economic freedom is good for a state's economy, then financial market participants who have the incentive to evaluate states' policies should respond favorably towards good governance institutions. In other words, financial markets should respond to the quality of the policies and adjust their assessments accordingly.

In valuable contributions to the empirical study of economic freedom, Calcagno and Benefield (2013) and Belasen et al. (2015) consider state bond ratings. ${ }^{5}$ They show that the EFNA index provides independent information that explains the rating of a state's bonds. Controlling for the fiscal health of the state, they show that higher levels of economic freedom are associated with improved bond ratings.

Hence, we extend their analysis by comparing and contrasting the EFNA and the GE-EFNA index. If the GE-EFNA scores is an improvement in evaluating economic policies, then our index should correlate strongly with state bond ratings.

We use Standard and Poor's bond ratings. In their rating system, the highest rating possible is given the AAA status. In 2014, for example, fourteen states obtained this level, while in 2009 eleven had this high rating. Less fiscally-sound states receive ratings of $\mathrm{AA}+, \mathrm{AA}, \mathrm{AA}-, \mathrm{A}+, \mathrm{A}$, or A- descending as the evaluated health worsens. In 2014 Illinois, for example, was scored as an A- (which is down from their 2013 rating of $\mathrm{A}$ ), while California received an $\mathrm{A}$ rating (which is an improvement from their 2013 A-rating).

To quantify the numerical rating, we assign a value of six to state-year observations that achieved an AAA rating, a five to a state-year observation that received an $\mathrm{AA}+$, decreasing down to a value of zero for state-year observations with an A- rating. Thus,

\footnotetext{
${ }^{5}$ Relatedly, Dove (2017) illustrates a relationship between state bond ratings and judicial independence measurements, which is an important related feature of economic freedom. Roychoudhury and Lawson (2010) establish a strong relationship between the EFW index and sovereign bond ratings.
} 
greater values correspond to more fiscally healthy states. Bond rating information between 2004 and 2013 are used.

As previously discussed, the EFNA and GE-EFNA scores between 2004 and 2013 are calculated. Specifically, we use the estimation in the second column of Table 4.2, which includes time and state fixed effects.

Additionally, as done in Calcagno and Benefield (2013) and Belasen et al. (2015) we control for a state's basic fiscal conditions of a state. Specifically, we collect tax revenue data from the Pew Charitable Trusts. ${ }^{6}$ The four quarter moving average data are used. We use Q4 of the year as the observation for each state. The data are adjusted for inflation and measured in the thousands. We also collect state population data from the U.S. Census. We divide the tax revenue by the state's population to generate the resulting real tax revenue per capita for each state in each year between 2004 and 2013. Table 4.4 provides the descriptive statistics for the variables used in the analysis.

In Table 4.4 the EFNA score can be compared to our GE-EFNA value. It is important to note that we present the score using the second estimation in Table 4.2. This model included state and year fixed effects. Thus, a time-invariant, geographicinvariant intercept term does not exist. To scale it to comparable values, we renormalized the economic freedom value so that the maximum and minimum values of the GE-EFNA and EFNA match. Thus, an affine transformation is used in Table 4.4 to have comparable scores. The EFNA index has a slightly lower mean and median term with a greater variance than our GE-EFNA index.

Furthermore, the tax revenue data is presented in whole thousand-dollars and in per capita terms for comparison. In both measurements, there is a substantial amount of variation. Some states generate only relatively modest tax revenues per person, while others are able to extract rather high amounts. For example, the maximum value for per capita tax revenue is Alaska in 2008 where pre-recession oil-

\footnotetext{
${ }^{6}$ For tax revenue data see http://www.pewtrusts.org/en/multimedia/datavisualizations/2014/fiscal-50\#ind0 and for population data see http://www.census.gov/popest/data/historical/2000s/vintage_2009/index.html.
} 
related, taxation is maximal. In fact, the top ten observations in value are all from Alaska and North Dakota. This suggests that a formal econometric investigation requires including state controls to differentiate natural resource rich states from the underlying direct effects of economic freedom on fiscal health.

Therefore, we estimate a fixed effects model with the bond rating as the dependent variable. State fixed effects are included to capture time-invariant features of the state, such as population, education, political institutions (such as tax and expenditure limits (Stallmann et al., 2012), natural resource availability, etc. Additionally, we include year fixed effects to account for macroeconomic factors that affect the country, such as inflation, interest rates, and recessions. Models differ in which economic freedom measurement is included. Table 4.5 provides the econometric results.

The first column considers the impact of the EFNA and GE-EFNA indices on the state's bond rating. Each is independently statistically significant. Improvements in a state's economic freedom score is associated with an improvement in that state's bond rating. Controlling for its EFNA value and tax revenue, the GE-EFNA score has a separate, positive effect.

If EFNA is dropped from the estimation, as is shown in II, the magnitude and statistical significance of GE-EFNA improves. Thus, it is a robust determinant of state bond ratings. Considering this total effect (both the direct and indirect effects), an increase in the GE-EFNA index by one unit increases the state bond rating by $22.5 \%$. Put another way, a one standard deviation increase in a state's GE-EFNA score increases the state's bond rating by just less than one-half of a standard deviation (0.45). Therefore, the effect is not only statistically significant, but it is economically significant as well.

In III, GE-EFNA is omitted. Comparing I and III, the goodness of fit measurements worsen. The R2 measurements reduce and the Akaike Information Criterion (AIC) and Hannan-Quinn Information Criterion (HQC) values grow larger. ${ }^{7}$ Hence,

\footnotetext{
${ }^{7}$ The AIC, HQC, and SC are the three common measurements of goodness of fit used in forecasting. Each provides a transformation of the residuals of the estimated model where lower values correspond to better-fitting models.
} 
the inclusion of the GE-EFNA score improves the model's predictive ability. The only goodness of fit measurement that does not improve is the Schwarz Criterion (SC). Looking across the three specifications, the best fitting model, according to the SC measurement, is the one that only includes GE-EFNA. Thus, one can safely argue that the growth-enhancing economic freedom score does a better job of explaining financial ratings of debt.

The final two columns consider the dynamic relationships. While the first three columns illustrate that GE-EFNA index is a better way to measure economic freedom's correlation with bond ratings, columns IV and V show that there is a persistence to the effect. Not only is the current level important, but so too is the previous year's score.

The specifications given in Table 4.5 present results from a fixed effects model. One may be concerned that this is not the most appropriate framework since the dependent variable takes a finite number of discrete values. Hence, the model can be re-estimated using either an ordered probit or an ordered logit model. Both of these models are more appropriate for an ordered variable like a bond rating. Additionally, the specifications we choose to report use state and year fixed effects to capture important, systematic differences between the states. Belasen et al. (2015) instead use labor market data to account for the economic conditions of the state. Thus, we re-estimate the model adding unemployment rate and labor force participation rates. These results provide the same picture as that presented in Table 4.5 and, therefore, are not reported here. Since the primary focus is on the goodness of fit, Table A2 in the appendix provides a comparison of the goodness of fit across the new specifications. As illustrated, the goodness of fit improves when GE-EFNA index is used to explain state bond ratings. 


\subsection{Conclusion}

The purpose of this article is to contribute to the literature by creating a GrowthEnhancing Economic Freedom of North America (GE-EFNA) index. We do so by creating a weighted composite of the EFNA index's three components. The weights correspond to those that "best fit" economic policy to real GDP per capita improvements. This index allows us to consider the nonlinearities and interaction effects between the three components of the EFNA index, unlike summing up the three major components, as done in the construction of the existing EFNA. Our procedure is able to capture interdependencies between policies and increasing returns to economic freedom.

In order to test whether GE-EFNA index performs well, we consider the relationship between economic freedom and state bond ratings, as done in Calcagno and Benefield (2013) and Belasen et al. (2015), using our GE-EFNA. The growth-enhancing index performs better than the standard EFNA index. It provides a better-fitting relationship with bond ratings. There is also an important dynamic relationship between lagged GE-EFNA values and current bond ratings. Given the result that assessments by financial market participants are better explained with our new index, it can be used to guide economic policy improvements.

This article has important policy implications. It adds to the growing literature using EFNA index as an explanatory variable for identifying the particular underlying area of economic policy which needs primary focus. We use the coefficients from the regression of the three areas of economic freedom on state-level GDP to calculate the marginal benefit achieved from increasing each component. This helps us to identify the particular area, for each state in U.S, which can be targeted to most improve economic well-being. Using data for the EFNA components in 2013, our results confirm that the targeted area for improving economic well-being vary across states.

We feel that our approach can guide not only economic policy, but lead to future research questions to be addressed. Alternative, normative objectives can be consid- 
ered. For example, if one wants to focus specifically on promoting entrepreneurial activities, the methods employed could be used to identify the source of the mostimpactful reforms a state should pursue. Also, a further investigation into the GEEFNA may be warranted. The analysis of a panel data set allows us to utilize both variation across states and across time to discover the best fitting relationship. Changes in policy, though, are endogenous. They are influenced by the economic and political conditions of the state, which differ across the country and change within a state over time. These environmental influences may drive economic growth. The potential endogeneity effects can be expected to feed back into the identification of which policy dimension provides the greatest marginal value. Taking them into account would improve the GE-EFNA index's usefulness. Finally, extending the techniques to cross-country differences in economic freedom, using for example the EFW index, may provide further insights. 
Table 4.1: Descriptive Statistics

\begin{tabular}{lrrrrrr}
\hline \multicolumn{1}{c}{ Variables } & Label & N & Mean & Std. Dev. & Min & Max \\
\hline Government Spending & A1 & 850 & 7.186 & 1.059 & 1.900 & 9.500 \\
Taxes & A2 & 850 & 6.594 & 0.749 & 4.500 & 8.500 \\
Labor Market Freedom & A3 & 850 & 6.972 & 0.637 & 5.100 & 8.700 \\
Real GDP per Capita & GDP & 850 & 44,733 & 8,476 & 28,368 & 74,289 \\
\hline
\end{tabular}

Note: Time Period: 2004-2013 
Table 4.2: Growth-Enhancing Economic Freedom

\begin{tabular}{|c|c|c|c|c|}
\hline & I & & II & \\
\hline A1 & -3.466 & $(0.58) * * *$ & -0.167 & $(0.20)$ \\
\hline A1sq & 0.184 & $(0.01) * * *$ & 0.036 & $(0.002)^{*}$ \\
\hline $\mathrm{A} 2$ & -3.517 & $(0.60)^{* * *}$ & -0.264 & $(0.22)$ \\
\hline $\mathrm{A} 2 \mathrm{sq}$ & 0.081 & $(0.01)^{* * *}$ & -0.001 & $(0.01)$ \\
\hline A3 & -3.022 & $(0.54)^{* * *}$ & -0.353 & $(0.22)$ \\
\hline A3sq & 0.032 & $(0.01)^{* *}$ & 0.007 & $(0.01)$ \\
\hline A1 x A2 & 0.452 & $(0.08) * * *$ & 0.010 & $(0.03)$ \\
\hline $\mathrm{A} 1 \times \mathrm{A} 3$ & 0.483 & $(0.08)^{* * *}$ & 0.024 & $(0.03)$ \\
\hline $\mathrm{A} 2 \times \mathrm{A} 3$ & 0.381 & $(0.08)^{* * *}$ & 0.034 & $(0.03)$ \\
\hline $\mathrm{A} 1 \times \mathrm{A} 2 \times \mathrm{A} 3$ & -0.069 & $(0.01)^{* * *}$ & -0.001 & $(0.01)$ \\
\hline State FEs? & No & & Yes & \\
\hline Year FEs? & No & & Yes & \\
\hline Rsq & 0.251 & & 0.697 & \\
\hline
\end{tabular}


Table 4.3: Marginal Impacts of Improved Economic Freedom

\begin{tabular}{lrrrrr}
\hline \multicolumn{1}{c}{ State } & Area in Need & MV_II & \multicolumn{1}{c}{ State } & Area in Need & MV_II \\
\hline Alabama & Area 2 & 2.03 & Montana & Area 2 & 2.03 \\
Alaska & Area 2 & 1.77 & Nebraska & Area 1 & 0.10 \\
Arizona & Area 3 & 0.10 & Nevada & Area 2 & 2.21 \\
Arkansas & Area 3 & 0.06 & New Hampshire & Area 1 & 0.15 \\
California & Area 3 & 0.01 & New Jersey & Area 3 & 0.06 \\
Colorado & Area 3 & 0.10 & New Mexico & Area 2 & 1.89 \\
Connecticut & Area 3 & 0.08 & New York & Area 3 & 0.00 \\
Delaware & Area 3 & 0.07 & North Carolina & Area 3 & 0.08 \\
Florida & Area 3 & 0.13 & North Dakota & Area 3 & 0.10 \\
Georgia & Area 3 & 0.09 & Ohio & Area 3 & 0.06 \\
Hawaii & Area 1 & 0.03 & Oklahoma & Area 1 & 0.10 \\
Idaho & Area 1 & 0.09 & Oregon & Area 2 & 2.00 \\
Illinois & Area 3 & 0.06 & Pennsylvania & Area 3 & 0.09 \\
Indiana & Area 3 & 0.09 & Rhode Island & Area 3 & 0.07 \\
Iowa & Area 3 & 0.08 & South Carolina & Area 3 & 0.07 \\
Kansas & Area 1 & 0.09 & South Dakota & Area 1 & 0.15 \\
Kentucky & Area 3 & 0.05 & Tennessee & Area 2 & 2.38 \\
Louisiana & Area 3 & 0.09 & Texas & Area 1 & 0.14 \\
Maine & Area 3 & 0.06 & Utah & Area 3 & 0.08 \\
Maryland & Area 3 & 0.10 & Vermont & Area 3 & 0.05 \\
Massachusetts & Area 3 & 0.09 & Virginia & Area 3 & 0.12 \\
Michigan & Area 2 & 2.09 & Washington & Area 2 & 1.89 \\
Minnesota & Area 3 & 0.06 & West Virginia & Area 2 & 1.86 \\
Mississippi & Area 2 & 1.97 & Wisconsin & Area 3 & 0.06 \\
Missouri & Area 1 & 0.11 & Wyoming & Area 2 & 2.09 \\
\hline
\end{tabular}


Table 4.4: Descriptive Statistics

\begin{tabular}{lrrrrr}
\hline & Mean & Std. Dev. & Median & \multicolumn{1}{c}{ Min } & \multicolumn{1}{c}{ Max } \\
\hline Bond Rating & 4.47 & 1.18 & 4 & 0 & 6 \\
EFNA & 6.89 & 0.59 & 6.91 & 5.28 & 8.31 \\
GE-EFNA & 7.19 & 0.51 & 7.17 & 5.28 & 8.31 \\
Tax Revenue (level) & $4,200,023$ & $5,279,062$ & $2,463,148$ & 345,095 & $36,411,696$ \\
(per capita) & 0.724 & 0.291 & 0.657 & 0.4086 & 3.850 \\
\hline Note: Time period: 2004-2013 & & & &
\end{tabular}

Note: Time period: 2004-2013 
Table 4.5: Economic Freedom and State Bond Rating

\begin{tabular}{lrrrrr}
\hline & \multicolumn{1}{c}{ I } & II & \multicolumn{1}{c}{ III } & \multicolumn{1}{c}{ IV } & \multicolumn{1}{c}{ V } \\
\hline EFNA & $0.572^{*}$ & & $1.028^{* * *}$ & & \\
& $(0.327)$ & & $(0.227)$ & & \\
GE-EFNA & $0.609^{*}$ & $1.007^{* * *}$ & & $0.727^{* * *}$ & $0.522^{*}$ \\
& $(0.315)$ & $(0.219)$ & & $(0.267)$ & $(0.303)$ \\
GE-EFNA lagged & & & & $0.447^{*}$ & $0.785^{* * *}$ \\
& & & & $(0.247)$ & $(0.299)$ \\
Tax Revenue & 0.219 & 0.204 & 0.251 & 0.180 & 0.079 \\
& $(0.158)$ & $(0.158)$ & $(0.158)$ & $(0.158)$ & $(0.164)$ \\
Tax Revenue lagged & & & & & $0.338^{* *}$ \\
& & & & & $(0.165)$ \\
\hline State FEs? & Yes & Yes & Yes & Yes & Yes \\
Year FEs? & Yes & Yes & Yes & Yes & Yes \\
LSDV Rsq & 0.8583 & 0.8572 & 0.8570 & 0.8584 & 0.8721 \\
Within Rsq & 0.1450 & 0.1383 & 0.1368 & 0.1456 & 0.1479 \\
AIC & 654.93 & 656.45 & 657.24 & 654.67 & 553.07 \\
HQC & 753.68 & 753.59 & 754.37 & 753.42 & 649.49 \\
SC & 905.46 & 902.88 & 903.66 & 905.19 & 796.55 \\
\hline
\end{tabular}

Note: Fixed Effects, dependent variable $=$ Bond Rating, $\mathrm{N}=449$, ${ }^{* * *} 1 \%$; ${ }^{* *}$ $5 \%, * 10 \%$ level of significance 
Table 4.6: Growth-Enhancing Economic Freedom

\begin{tabular}{|c|c|c|c|c|c|c|c|}
\hline State & GE-EFNA & GE-EFNA Rank & EFNA Rank & State & GE-EFNA & GE-EFNA Rank & EFNA Rank \\
\hline Alabama & 7.07 & 25 & 23 & Montana & 7.03 & 29 & 22 \\
\hline Alaska & 5.66 & 50 & 49 & Nebraska & 7.92 & 3 & 10 \\
\hline Arizona & 7.52 & 10 & 11 & Nevada & 7.45 & 15 & 7 \\
\hline Arkansas & 7.02 & 30 & 34 & New Hampshire & 8.19 & 1 & 1 \\
\hline California & 6.41 & 49 & 48 & New Jersey & 6.95 & 32 & 38 \\
\hline Colorado & 7.51 & 11 & 8 & New Mexico & 6.48 & 47 & 47 \\
\hline Connecticut & 7.34 & 18 & 26 & New York & 6.47 & 48 & 50 \\
\hline Delaware & 6.70 & 43 & 32 & North Carolina & 7.28 & 20 & 20 \\
\hline Florida & 7.92 & 4 & 3 & North Dakota & 7.30 & 19 & 16 \\
\hline Georgia & 7.50 & 12 & 14 & Ohio & 6.51 & 46 & 41 \\
\hline Hawaii & 7.25 & 22 & 46 & Oklahoma & 7.59 & 9 & 13 \\
\hline Idaho & 7.48 & 14 & 19 & Oregon & 6.51 & 45 & 44 \\
\hline Illinois & 7.04 & 27 & 31 & Pennsylvania & 7.05 & 26 & 21 \\
\hline Indiana & 7.40 & 16 & 17 & Rhode Island & 6.76 & 41 & 35 \\
\hline Iowa & 7.15 & 24 & 24 & South Carolina & 6.76 & 40 & 27 \\
\hline Kansas & 7.81 & 6 & 18 & South Dakota & 8.09 & 2 & 2 \\
\hline Kentucky & 6.60 & 44 & 39 & Tennessee & 7.60 & 8 & 5 \\
\hline
\end{tabular}

Note: Time Period: 2013 
Table 4.7: Goodness of Fit of Alternative Specifications

\begin{tabular}{llrrr}
\hline Model & Explanatory variables & AIC & HQC & SC \\
\hline Ordered Logit & EFNA \& GE-EFNA & 1260.00 & 1274.57 & 1296.98 \\
& GE-EFNA only & 1300.69 & 1313.64 & 1333.56 \\
& EFNA only & 1268.62 & 1281.58 & 1301.49 \\
\hline Ordered Probit & EFNA \& GE-EFNA & 1250.98 & 1265.56 & 1287.97 \\
& GE-EFNA only & 1294.87 & 1307.82 & 1327.74 \\
& EFNA only & 1258.62 & 1271.58 & 1291.50 \\
\hline Ordered Logit with & EFNA \& GE-EFNA & 1249.18 & 1267.00 & 1294.38 \\
ur and lfpr & GE-EFNA only & 1287.66 & 1303.85 & 1328.75 \\
& EFNA only & 1262.94 & 1279.14 & 1304.03 \\
\hline
\end{tabular}

Note: Time Period: 2004-2013 
Table 4.8: Growth-Enhancing Economic Freedom

\begin{tabular}{lrlrl}
\hline & \multicolumn{3}{c}{ I } & II \\
\hline A1 & -3.466 & $(0.58)^{* * *}$ & -0.167 & $(0.20)$ \\
A1sq & 0.184 & $(0.01)^{* * *}$ & 0.036 & $(0.002)^{*}$ \\
A2 & -3.517 & $(0.60)^{* * *}$ & -0.264 & $(0.22)$ \\
A2sq & 0.081 & $(0.01)^{* * *}$ & -0.001 & $(0.01)$ \\
A3 & -3.022 & $(0.54)^{* * *}$ & -0.353 & $(0.22)$ \\
A3sq & 0.032 & $(0.01)^{* *}$ & 0.007 & $(0.01)$ \\
A1 x A2 & 0.452 & $(0.08)^{* * *}$ & 0.010 & $(0.03)$ \\
A1 x A3 & 0.483 & $(0.08)^{* * *}$ & 0.024 & $(0.03)$ \\
A2 x A3 & 0.381 & $(0.08)^{* * *}$ & 0.034 & $(0.03)$ \\
A1 x A2 x A3 & -0.069 & $(0.01)^{* * *}$ & -0.001 & $(0.01)$ \\
\hline State FEs? & No & & \multicolumn{3}{c}{ Yes } \\
Year FEs? & No & & Yes \\
Rsq & 0.251 & & 0.697 \\
\hline
\end{tabular}

Note: Dependent Variable $=$ real GDP per capita. $* * * 1 \% ; * * 5 \%, * 10 \%$ level of significance. 


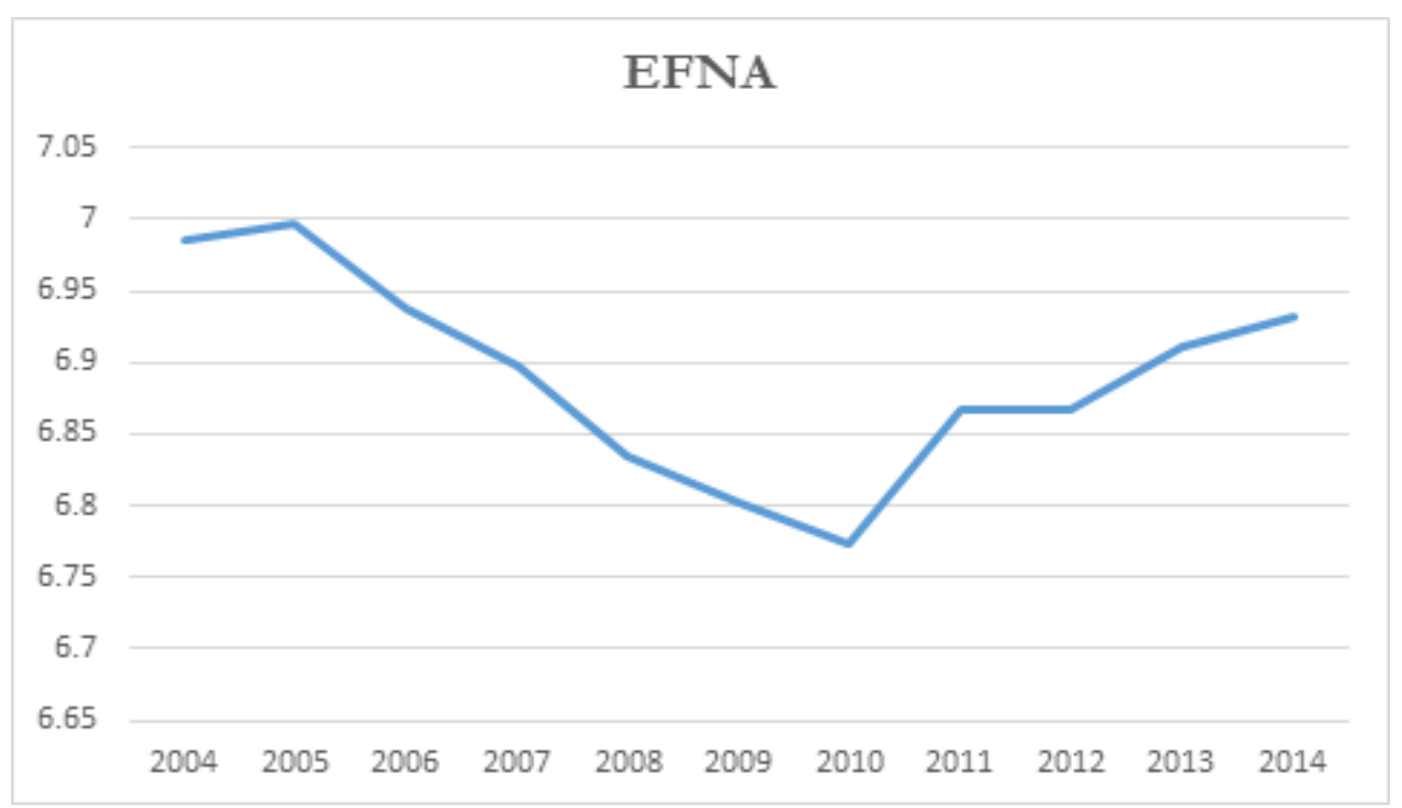

Figure 4.1: Economic Freedom over Time 


\section{Chapter 5}

\section{Conclusion}

The purpose of this thesis is to address the role of institutional qualities in terms of firm dynamics, entrepreneurship and policy making. The three essays intend to analyze whether over regulation act as an impediment towards higher economic growth resulting from lower firm survival or lower entrepreneurship rate.

In Chapter 2, I analyze the effect of industry level regulation on firm survival using data for 4928 start-up firms starting from 2004 to 2011 (or till exit). The results confirm that the large firms having more than 100 employees have higher probability of surviving in the market with increasing federal regulation. The large firms having larger scale of operation can exploit economies of scale whereas the smaller sized firms often fail to comply to the higher fixed cost of regulation and are more probable to leave the market with increasing regulation.

In Chapter 3, I investigate the relationship between institutional qualities and latent entrepreneurship using data for entrepreneurial intentions from the GEM Report, for 79 countries (from 2001 to 2016). The findings of this paper state that a stricter labor regulation may encourage higher latent entrepreneurship whereas easier credit regulation has a positive effect on latent entrepreneurship. This signals towards necessity based entrepreneurship in transition economies. The countries having easier credit regulation and more secure labor regulation witnesses higher rate of latent entrepreneurs compared to those having stricter credit regulation and more lenient 
labor regulation.

In Chapter 4, we create a Growth-Enhancing Economic Freedom of North America (GE-EFNA) index by creating a weighted composite of the Economic Freedom of North America index's three components, the weights signaling towards higher real GDP per capita. This index helps us to identify the particular area, for each state in U.S, which can be targeted to maximize economic well-being. Using data for the EFNA components in 2013, our results confirm that the targeted area for improving economic well-being vary across states. 


\section{References}

Acemoglu, D. and Angrist, J. D. (2001). Consequences of employment protection? the case of the Americans with Disabilities Act. Journal of Political Economy, 109(5):915-957.

Agarwal, R. and Audretsch, D. B. (2001). Does entry size matter? The impact of the life cycle and technology on firm survival. Journal of Industrial Economics, 49(1):21-43.

Al-Ubaydli, O. and McLaughlin, P. A. (2017). Regdata: A numerical database on industry-specific regulations for all US industries and federal regulations, 19972012. Regulation and Governance, 11(1):109-123.

Angulo-Guerrero, M. J., Pérez-Moreno, S., and Abad-Guerrero, I. M. (2017). How economic freedom affects opportunity and necessity entrepreneurship in the OECD countries. Journal of Business Research, 73:30-37.

Apergis, N., Dincer, O., and Payne, J. E. (2014). Economic freedom and income inequality revisited: Evidence from a panel error correction model. Contemporary Economic Policy, 32(1):67-75.

Ardagna, S. and Lusardi, A. (2008). Explaining international differences in entrepreneurship: The role of individual characteristics and regulatory constraints. National Bureau of Economic Research.

Ardagna, S. and Lusardi, A. (2009). Where does regulation hurt? evidence from new businesses across countries. Technical report, National Bureau of Economic Research Working Paper No. 14012.

Ardagna, S. and Lusardi, A. (2010). Heterogeneity in the effect of regulation on entrepreneurship and entry size. Journal of the European Economic Association, 8(2-3):594-605. 
Ariff, M., Husna, A., Bidin, Z., Sharif, Z., and Ahmad, A. (2010). Predicting entrepreneurship intention among Malay university accounting students in Malaysia. UNITAR E-Journal, 6(1):1-10.

Ashby, N. J. (2007). Economic freedom and migration flows between US states. Southern Economic Journal, 134(3-4):677-697.

Ashby, N. J. and Sobel, R. S. (2008). Income inequality and economic freedom in the US states. Public Choice, 134(3):329-346.

Åstebro, T. and Bernhardt, I. (2003). Start-up financing, owner characteristics, and survival. Journal of Economics and Business, 55(4):303-319.

Audretsch, D. B. and Mahmood, T. (1994). The rate of hazard confronting new firms and plants in US manufacturing. Review of Industrial Organization, 9(1):41-56.

Bailey, J. and Thomas, D. (2015). Regulating away competition. Mercatus Center Working Paper.

Beaulier, S., Elder, R., Han, C., and Hall, J. C. (2016). An ordinal ranking of economic institutions. Applied Economics, 48(26):2482-2490.

Belasen, A. R., Hafer, R. W., and Jategaonkar, S. P. (2015). Economic freedom and state bond ratings. Contemporary Economic Policy, 33(4):668-677.

Bennett, D. L. and Vedder, R. K. (2013). A dynamic analysis of economic freedom and income inequality in the 50 US states: Empirical evidence of a parabolic relationship. Journal of Regional Analysis and Policy, 43(1):42-55.

Berkowitz, D. and DeJong, D. N. (2005). Entrepreneurship and post-socialist growth. Oxford Bulletin of Economics and Statistics, 67(1):25-46.

Bezmen, T. L. and Depken, C. A. (2006). Influences on software piracy: Evidence from the various United States. Economics Letters, 90(3):356-361. 
Bjørnskov, C. and Foss, N. (2010). Economic freedom and entrepreneurial activity: Some cross-country evidence. In Freytag, A. and Thurik, R., editors, Entrepreneurship and Culture, pages 201-225. Springer.

Bradford, C. S. (2004). Does size matter? An economic analysis of small business exemptions from regulation. Journal of Small ES Emerging Business Law, 8:1-38.

Brunetti, A., Kisunko, G., and Weder, B. (1997). Institutional obstacles to doing business: Region-by-region results from a worldwide survey of the private sector. World Bank Policy Research Working Paper 1759.

Calcagno, P. T. and Benefield, J. D. (2013). Economic freedom, the cost of public borrowing, and state bond ratings. Journal of Financial Economic Policy, 5(1):7285.

Calcagno, P. T. and Sobel, R. S. (2014). Regulatory costs on entrepreneurship and establishment employment size. Small Business Economics, 42(3):541-559.

Campbell, N. D., Fayman, A., and Heriot, K. C. (2010). Including US state government regulation in the Economic Freedom of North America index. Journal of Private Enterprise, 25(2):165-186.

Campbell, N. D., Heriot, K. C., Jauregui, A., and Mitchell, D. T. (2012). Which state policies lead to US firm exits? Analysis with the economic freedom index. Journal of Small Business Management, 50(1):87-104.

Campbell, N. D., Rogers, T. M., and Heriot, K. C. (2007). The economic freedom index as a determinant of firm births and firm deaths. Southwest Business 86 Economics Journal, 16(1):37-50.

Capelleras, J.-L., Mole, K. F., Greene, F. J., and Storey, D. J. (2008). Do more heavily regulated economies have poorer performing new ventures? Evidence from Britain and Spain. Journal of International Business Studies, 39(4):688-704. 
Carboni, M., Fiordelisi, F., Ricci, O., and Lopes, F. S. S. (2017). Surprised or not surprised? The investors' reaction to the comprehensive assessment preceding the launch of the banking union. Journal of Banking \& Finance, 74:122-132.

Carlos Díaz-Casero, J., Ángel Manuel Díaz-Aunión, D., Cruz Sanchez-Escobedo, M., Coduras, A., and Hernández-Mogollón, R. (2012). Economic freedom and entrepreneurial activity. Management Decision, 50(9):1686-1711.

Cebula, R. J. (2014). The impact of economic freedom and personal freedom on net in-migration in the US: A state-level empirical analysis, 2000 to 2010. Journal of Labor Research, 35(1):88-103.

Cebula, R. J. and Alexander, G. (2015). An exploratory empirical note on the impact of labour market freedom on the female labour force participation rate in the US. Applied Economics Letters, 22(8):632-636.

Cebula, R. J. and Clark, J. (2011). Migration, economic freedom, and personal freedom: An empirical analysis. Journal of Private Enterprise, 27(1):43-62.

Coffey, B., McLaughlin, P. A., and Peretto, P. F. (2016). The cumulative cost of regulations. Duke I\&E Research Paper No. 2016-45.

Cole, R. A. and Sokolyk, T. (2013). How do start-up firms finance their assets? evidence from the Kauffman firm surveys. SSRN Working Paper.

Coleman, S., Cotei, C., and Farhat, J. (2013). A resource-based view of new firm survival: New perspectives on the role of industry and exit route. Journal of Developmental Entrepreneurship, 18(01):1350002-1-1350002-25.

Compton, R. A., Giedeman, D. C., and Hoover, G. A. (2014). A distributional analysis of the benefits of economic freedom. European Journal of Political Economy, $33: 121-133$.

Cumming, D. and Li, D. (2013). Public policy, entrepreneurship, and venture capital in the United States. Journal of Corporate Finance, 23:345-367. 
Davies, A. (2014). Regulation and productivity. Mercatus Center Working Paper.

Dawson, J. W. and Seater, J. J. (2013). Federal regulation and aggregate economic growth. Journal of Economic Growth, 18(2):137-177.

De Rugy, V. and Davies, A. (2009). Midnight regulations and the Cinderella effect. Journal of Socio-Economics, 38(6):886-890.

Desai, M., Gompers, P., and Lerner, J. (2003). Institutions, capital constraints and entrepreneurial firm dynamics: Evidence from Europe. National Bureau of Economic Research Working Paper No. 10165.

Detotto, C. and McCannon, B. C. (2017). Economic freedom and public, nonmarket institutions: Evidence from criminal prosecution. Economics of Governance, 18(2):107-128.

Djankov, S., La Porta, R., Lopez-de Silanes, F., and Shleifer, A. (2002). The regulation of entry. Quarterly Journal of Economics, 117(1):1-37.

Dove, J. A. (2017). Judicial independence and US state bond ratings: An empirical investigation. Public Budgeting \& Finance, Forthcoming.

Dunne, T., Roberts, M. J., and Samuelson, L. (1988). Patterns of firm entry and exit in US manufacturing industries. RAND Journal of Economics, 19(4):495-515.

Fairlie, R. W. and Robb, A. M. (2007). Why are black-owned businesses less successful than white-owned businesses? The role of families, inheritances, and business human capital. Journal of Labor Economics, 25(2):289-323.

Gai, Y. and Minniti, M. (2015). External financing and the survival of black-owned start-ups in the US. Eastern Economic Journal, 41(3):387-410.

Geroski, P. A., Mata, J., and Portugal, P. (2010). Founding conditions and the survival of new firms. Strategic Management Journal, 31(5):510-529. 
Goetz, S. J. and Rupasingha, A. (2009). Determinants of growth in non-farm proprietor densities in the US, 1990-2000. Small Business Economics, 32(4):425-438.

Gohmann, S. F. (2012). Institutions, latent entrepreneurship, and self-employment: An international comparison. Entrepreneurship Theory and Practice, 36(2):295321.

Goldschlag, N. and Tabarrok, A. T. (2014). Is regulation to blame for the decline in American entrepreneurship? SSRN Working Paper.

Gwartney, J. (2009). Institutions, economic freedom, and cross-country differences in performance. Southern Economic Journal, 75(4):937-956.

Gwartney, J. and Lawson, R. (2008). Economic Freedom of the World: 2008 Annual Report. Fraser Institute, Vancouver.

Gwartney, J. D., Holcombe, R. G., and Lawson, R. A. (2004). Economic freedom, institutional quality, and cross-country differences in income and growth. Cato Journal, 24(3):205-234.

Gwartney, J. D., Lawson, R., and Block, W. (1996). Economic Freedom of the World, 1975-1995. Fraser Institute, Vancouver.

Hall, J. C. and Sobel, R. S. (2008). Institutions, entrepreneurship, and regional differences in economic growth. Southern Journal of Entrepreneurship, 1(1):69-96.

Haveman, H. A. (1995). The demographic metabolism of organizations: Industry dynamics, turnover, and tenure distributions. Administrative Science Quarterly, 40(4):586-618.

Heckelman, J. C. and Stroup, M. D. (2002). Which economic freedoms contribute to growth? Reply. Kyklos, 55(3):417-420.

Heller, L. R. and Stephenson, E. (2014). Economic freedom and labor market conditions: Evidence from the states. Contemporary Economic Policy, 32(1):56-66. 
Henrekson, M. (2014). How labor market institutions affect job creation and productivity growth. IZA World of Labor, May:1-10.

Ionescu, L. (2014). The adverse effects of corruption on growth and development. Economics, Management and Financial Markets, 9(4):125-130.

Jones, S. K. and Stroup, M. D. (2013). Economic freedom and the mispricing of single-state municipal bond closed-end funds. Journal of Economics and Finance, $37(2): 173-187$.

Justesen, M. K. (2008). The effect of economic freedom on growth revisited: New evidence on causality from a panel of countries 1970-1999. European Journal of Political Economy, 24(3):642-660.

Klapper, L., Laeven, L., and Rajan, R. (2006). Entry regulation as a barrier to entrepreneurship. Journal of Financial Economics, 82(3):591-629.

Klapper, R. and Leger-Jarniou, C. (2006). Entrepreneurship intention among French Grande École and university students: An application of Shapero's model. Industry and Higher Education, 20(2):97-110.

Kreft, S. F. and Sobel, R. S. (2005). Public policy, entrepreneurship, and economic freedom. Cato Journal, 25(3):595-616.

Lucas Jr, R. E. (1978). On the size distribution of business firms. Bell Journal of Economics, 9(2):508-523.

Mata, J. and Portugal, P. (1994). Life duration of new firms. Journal of Industrial Economics, 42(3):227-245.

McKeague, I. W. and Sasieni, P. D. (1994). A partly parametric additive risk model. Biometrika, 81(3):501-514. 
Mitchell, W. (1994). The dynamics of evolving markets: The effects of business sales and age on dissolutions and divestitures. Administrative Science Quarterly, $39(4): 575-602$.

Mulholland, S. E. and Hernández-Julián, R. (2013). Does economic freedom lead to selective migration by education? Journal of Regional Analysis 6 Policy, 43(1):6587.

Nooteboom, B. (1993). Firm size effects on transaction costs. Small Business Economics, 5(4):283-295.

Nyström, K. (2008). The institutions of economic freedom and entrepreneurship: Evidence from panel data. Public Choice, 136(3):269-282.

Ovaska, T., Sobel, R. S., et al. (2005). Entrepreneurship in post-socialist economies. Journal of Private Enterprise, 21(1):8-28.

Pearson, D., Nyonna, D., and Kim, K.-J. (2012). The relationship between economic freedom, state growth and foreign direct investment in US states. International Journal of Economics and Finance, 4(10):140-146.

Peltzman, S. (1976). Toward a more general theory of regulation. Journal of Law and Economics, 19(2):211-240.

Powell, B. (2002). Economic freedom and growth: The case of the Celtic tiger. Cato Journal, 22(3):431-448.

Reynolds, P. D., Hay, M., and Camp, S. M. (1999). Global Entrepreneurship Monitor. Kauffman Center for Entrepreneurial Leadership, Kansas City.

Robb, A. M. and Robinson, D. T. (2014). The capital structure decisions of new firms. Review of Financial Studies, 27(1):153-179.

Rode, M. and Coll, S. (2012). Economic freedom and growth: Which policies matter the most? Constitutional Political Economy, 23(2):95-133. 
Roychoudhury, S. and Lawson, R. A. (2010). Economic freedom and sovereign credit ratings and default risk. Journal of Financial Economic Policy, 2(2):149-162.

Schumpeter, J. A. (1934). The Theory of Economic Development. Harvard University Press, Cambridge.

Sharma, A. and Kesner, I. F. (1996). Diversifying entry: Some ex ante explanations for postentry survival and growth. Academy of Management Journal, 39(3):635677.

Sobel, R. S. (2008). Testing Baumol: Institutional quality and the productivity of entrepreneurship. Journal of Business Venturing, 23(6):641-655.

Sobel, R. S., Clark, J., and Lee, D. R. (2007). Freedom, barriers to entry, entrepreneurship, and economic progress. Review of Austrian Economics, 20(4):221236 .

Stallmann, J. I., Deller, S., Amiel, L., and Maher, C. (2012). Tax and expenditure limitations and state credit ratings. Public Finance Review, 40(5):643-669.

Stein, B. (1974). Size, Efficiency, and Community Enterprise. Transaction Publishers, Piscataway.

Stevenson, H. H. (1983). A Perspective on Entrepreneurship. Harvard Business Review Case Studies, Cambridge.

Stigler, G. J. (1971). The theory of economic regulation. Bell Journal of Economics, $2(1): 3-21$.

Stocker, M. L. (2005). Equity returns and economic freedom. Cato Journal, 25(3):583594.

Sutton, J. (1997). Gibrat's legacy. Journal of Economic Literature, 35(1):40-59.

Thomas, L. G. (1990). Regulation and firm size: FDA impacts on innovation. RAND Journal of Economics, 21(4):497-517. 
Tullock, G. (1967). The welfare costs of tariffs, monopolies, and theft. Wster Economic Journal, 5(3):224-232.

Van Stel, A., Storey, D. J., and Thurik, A. R. (2007). The effect of business regulations on nascent and young business entrepreneurship. Small Business Economics, 28(2):171-186.

Watkins, T. and Yandle, B. (2010). Can freedom and knowledge economy indexes explain go-getter migration patterns? Journal of Regional Analysis 83 Policy, 40(2):104-115.

Wiseman, T. (2017). Economic freedom and growth in US state-level market incomes at the top and bottom. Contemporary Economic Policy, 35(1):93-112.

Wiseman, T. and Young, A. T. (2013). Economic freedom, entrepreneurship, \& income levels: Some US state-level empirics. American Journal of Entrepreneurship, 6(1):104-124.

Zacharakis, A. L., Bygrave, W. D., and Shepherd, D. A. (2000). Global Entrepreneurship Monitor: 1999 Executive Report. Kauffman Center for Entrepreneurial Leadership, Kansas City.

Zain, Z. M., Akram, A. M., and Ghani, E. K. (2010). Entrepreneurship intention among Malaysian business students. Canadian Social Science, 6(3):34-44. 